NBER WORKING PAPER SERIES

\title{
PUBLIC HEALTH INSURANCE EXPANSIONS AND HOSPITAL TECHNOLOGY ADOPTION
}

\author{
Seth Freedman \\ Haizhen Lin \\ Kosali Simon \\ Working Paper 20159 \\ http://www.nber.org/papers/w20159
NATIONAL BUREAU OF ECONOMIC RESEARCH
1050 Massachusetts Avenue
Cambridge, MA 02138 \\ May 2014
}

We are grateful to Jean Roth for assistance with the American Hospital Association data. Freedman thanks the Robert Wood Johnson Foundation (RWJF) for funding support. We also thank Judy Hellerstein, Jill Horwitz, Kevin Lang, Sam Kleiner, Tim Moore, Edward Norton, Jeff Prince, and Marc Rysman; conference participants at the 2011 Association of Public Policy Analysis and Management (APPAM), 2012 American Economic Association (AEA), 2012 American Society of Health Economists (ASHEcon), and RWJ Scholars Program meetings; and seminar participants at Dartmouth College, George Washington University, and University of Chicago for helpful comments and suggestions. The views expressed herein are those of the authors and do not necessarily reflect the views of the National Bureau of Economic Research.

NBER working papers are circulated for discussion and comment purposes. They have not been peerreviewed or been subject to the review by the NBER Board of Directors that accompanies official NBER publications.

(C) 2014 by Seth Freedman, Haizhen Lin, and Kosali Simon. All rights reserved. Short sections of text, not to exceed two paragraphs, may be quoted without explicit permission provided that full credit, including () notice, is given to the source. 
Public Health Insurance Expansions and Hospital Technology Adoption

Seth Freedman, Haizhen Lin, and Kosali Simon

NBER Working Paper No. 20159

May 2014

JEL No. I11,I13,I18

\begin{abstract}
$\underline{\text { ABSTRACT }}$
This paper explores the effects of public health insurance expansions on hospitals' decisions to adopt medical technology. Specifically, we test whether the expansion of Medicaid eligibility for pregnant women during the 1980s and 1990s affects hospitals' decisions to adopt neonatal intensive care units (NICUs). While the Medicaid expansion provided new insurance to a substantial number of pregnant women, prior literature also finds that some newly insured women would otherwise have been covered by more generously reimbursed private sources. This leads to a theoretically ambiguous net effect of Medicaid expansion on a hospital's incentive to invest in technology. Using American Hospital Association data, we find that on average, Medicaid expansion has no statistically significant effect on NICU adoption. However, we find that in geographic areas where more of the newly Medicaid-insured may have come from the privately insured population, Medicaid expansion slows NICU adoption. This holds true particularly when Medicaid payment rates are very low relative to private payment rates. This finding is consistent with prior evidence on reduced NICU adoption from increased managed-care penetration. We conclude by providing suggestive evidence on the health impacts of this deceleration of NICU diffusion, and by discussing the policy implications of our work for insurance expansions associated with the Affordable Care Act.
\end{abstract}

\author{
Seth Freedman \\ Kosali Simon \\ Indiana University \\ 1315 E. 10th St., SPEA 355 \\ Bloomington, IN 47405 \\ School of Public and Environmental Affairs \\ Indiana University \\ freedmas@indiana.edu \\ Rm 359 \\ 1315 East Tenth Street \\ Bloomington, IN 47405-1701 \\ Haizhen Lin \\ Department of Business Economics \\ and NBER \\ and Public Policy \\ simonkos@indiana.edu \\ Kelley School of Business \\ Indiana University \\ 1309 E. Tenth St. \\ Bloomington, IN 47401 \\ hzlin@indiana.edu
}




\section{Introduction}

The development and diffusion of medical technology has been a primary driver of health care cost growth during recent decades (Newhouse 1992; Fuchs 1996; Cutler 2005). Since the 1960s there have also been dramatic changes in the U.S. health insurance landscape. Due in part to growth in private insurance, the introduction of Medicare and Medicaid, and subsequent expansions of the Medicaid program, 84 percent of Americans had health insurance in 2011 (DeNavas-Walt et al. 2012). Weisbrod (1991) argues that technology advancement and insurance expansion are intimately linked: the availability of expensive, lifesaving technology increases consumer demand for health insurance, and the ability of patients to pay for expensive medical care with insurance increases the incentives to produce and adopt new medical technology. Given this theoretical endogeneity, empirically estimating the effect of one on the other is difficult. Finkelstein (2007) finds convincing evidence that the introduction of Medicare drastically increased hospital spending above and beyond what would be predicted using patient-demand elasticities implied by the RAND Health Insurance Experiment, suggesting additional supply-side responses on the part of hospitals. She provides evidence that some of this additional supplyside response may be due to technology adoption by hospitals, but this finding is only suggestive as a result of data limitations during the period she studies. ${ }^{1}$

In this paper we exploit exogenous changes in Medicaid eligibility to directly estimate the causal effect of the availability of public health insurance on technology adoption by hospitals. We provide evidence from a period of substantial Medicaid eligibility expansion among low-income pregnant women by examining hospitals' decisions to adopt a form of technology that appeals directly to patients undergoing childbirth: neonatal intensive care units (NICUs). In addition to providing the first direct empirical evidence of hospital technology adoption reactions to public health insurance expansions in the U.S., studying supply-side responses to Medicaid expansions fills an important gap in the literature. First, Medicaid covered about 20 percent of all Americans in 2010 and accounted for about 15 percent of

\footnotetext{
${ }^{1}$ Chou, Liu, and Hammitt (2004) find that the introduction of national health insurance in Taiwan also increased hospitals' adoption of medical technology.
} 
national health care spending (DeNavas-Walt et al. 2012; Kaiser 2012). For this reason it is important to understand how hospitals respond to Medicaid expansions, especially as it may be very different from their responses to Medicare. Medicaid pays providers much less than Medicare does (Norton and Zuckerman 2000), thus possibly leading to different supply-side reactions. Additionally, while Medicaid expansions insured a substantial number of otherwise-uninsured pregnant women, some newly covered women came from the rolls of private sources that are more generous in their reimbursements. ${ }^{2}$ Dave at al. (2011) and Dubay and Kenney (1997) both find private insurance crowd-out estimates close to 50 percent for groups of pregnant women affected by Medicaid expansions. These forces may lead Medicaid to decrease the profitability of technology adoption, as did the rollout of managed care during the 1990s (Baker 2001; Baker and Phibbs 2002). Due to crowd-out, the net effect of Medicaid expansion on hospitals' incentives to invest in technology is ambiguous.

Understanding the supply-side responses to Medicaid expansions also sheds light on the expansion of the program under the Affordable Care Act (ACA). Starting in 2014 at state discretion, Medicaid programs have opened to all non-elderly adults in families with incomes less than 138 percent of the federal poverty level, which amounted to about $\$ 32,500$ for a family of four in 2013 . This expansion is projected to insure a total of 13 million individuals by 2024 (Congressional Budget Office 2014). We contribute to understanding the possible technology adoption consequences of new Medicaid expansions by examining the effects of past Medicaid expansions.

We proceed in this paper by first developing an analytical model to illustrate how incumbent hospitals' NICU adoption decisions might change following Medicaid eligibility expansions. We consider both the insurance-expansion effect and the Medicaid crowd-out effect, and conclude that the impact of Medicaid expansions on NICU adoption is ambiguous and depends on which of these two effects dominates. We also draw guidance from this model to help us empirically distinguish between the two effects based on how the eligibility expansions interact with local market characteristics, such as the pre-

\footnotetext{
${ }^{2}$ It is important to note that while Medicaid is less generous than private insurers from the provider perspective (Currie et al. 1995), Medicaid imposes lower cost sharing for pregnant patients than private insurance does. As Gruber (2008) puts it, Medicaid "provides the best insurance money can’t buy."
} 
expansion insurance rate and reimbursement ratios between private and Medicaid patients.

In our empirical analysis we use data for 1985 to 1996 from the American Hospital Association (AHA), a source covering virtually all hospitals in the U.S., and consider changes in Medicaid eligibility over time and across states for pregnant women. We find that on average, state-level Medicaid expansions have no effect on the likelihood that a hospital will offer a NICU. However, this effect varies greatly across hospitals according to certain characteristics of their state, which plausibly proxy for variation in private insurance prevalence absent the Medicaid expansions. We find that Medicaid expansions slow NICU diffusion in areas where we expect crowd-out to be strongest. We also find that this result of slowed NICU diffusion is driven by states in which the Medicaid reimbursement generosity is lowest as compared to private-pay rates. These findings are consistent with our expectation that the crowd-out of public coverage in these states have the largest negative impact on incentives to profitably invest in technology designed to attract maternal deliveries.

Although it is reasonable to expect a positive effect on NICU adoption in areas where the insurance-expansion effect is likely to dominate the Medicaid crowd-out effect, we find little evidence of acceleration. In areas where we expect relatively less crowd-out, we find no impact of eligibility changes on NICU provision, except in areas with extremely low pre-expansion insurance rates. Even in states with Medicaid payment rates closer to private levels and low expected crowd-out, we do not find evidence of increased NICU adoption. One possible explanation for this finding is that Medicaid payment rates are still too low as compared to the private rates to incentivize adoption in these markets. We also find that Medicaid expansions do not impact hospitals' market participation decisions and that Medicaid eligibility's effect on NICU adoption is primarily driven by incumbent hospitals.

We conclude our paper by providing suggestive evidence on the health impact of the deceleration of NICU diffusion in certain regions and by discussing the policy implications of our findings. Because current Medicaid expansions are not identical in nature to these past expansions, our findings also underline the need to continue studying the impact of insurance expansions on technology adoption under the ACA. 


\section{Background}

\section{A. Previous Literature}

The literature on the supply-side responses to public insurance expansions is relatively sparse compared to the literature that estimates the demand-side responses to expansions. Except for Finkelstein's (2007) examination of hospital expenditures, the supply-side literature has focused on innovation rather than provider-level decisions. Acemoglu et al. (2006) find that the introduction of Medicare for non-prescription-drug health care in 1965 did not increase demand for new prescription drugs enough to result in pharmaceutical innovation. However, according to Blume-Kohout and Sood (2008), pharmaceutical research and development accelerated when Medicare began covering outpatient prescription drugs through Part D. Finkelstein (2004) finds that public health initiatives, including Medicare coverage of influenza vaccines, led to increased vaccine-related clinical trials. Clemens (2012) finds increased medical equipment patenting in response to the introduction of Medicare and Medicaid.

While others have found that insurance expansions spur innovation overall, Hult and Philipson (2012) point out that returns to innovation should be non-monotonic as public insurance eligibility expands through the income distribution. Eligibility expansions increase demand for care, and this effect is likely to be particularly strong at the low end of the income distribution. Eligibility expansions at higher levels of income are less likely to impact demand and are likely to result in lower payment rates to providers than previous sources of payment held by higher-income individuals. While the Medicaid expansions we study still affect relatively low-income populations, if Medicaid replaces higherreimbursing private coverage for some individuals, the expansion may have a limited or even negative net impact on hospitals' incentives to invest in new technologies.

In terms of provider behavior, a set of papers has examined the impact of Medicaid fees on the amount of time physicians spend with patients and on the setting in which care occurs (Decker 2007, 2009), but we are aware of only one paper that studies supply-side responses to eligibility expansions: Garthwaite (2012) studies physicians' labor-supply responses to Children's Health Insurance Program 
(CHIP) expansions. Research is still needed on other supply-side responses to Medicaid expansion, such as investments in new facilities or technology adoption, since technology diffusion has been a major driver of health care cost growth (Newhouse 1992; Fuchs 1996; Cutler 2005).

In the area of private-sector insurance, the proliferation of managed care has been found to slow adoption (Baker 2001; Baker and Phibbs 2002). These previous findings are consistent with Weisbrod's (1991) hypothesis that the effect of insurance on technology adoption will depend on how that insurer pays; while Medicare caused a large shift out in the demand curve for medical care, managed care reduced patient and physician incentives for utilizing technology, and health care providers responded by changing their technology adoption decisions. These findings are also consistent with Chandra and Skinner's (2011) model of productivity growth in health care, in which insurance impacts the extent and type of technology diffusion through both patient and provider incentives. Theoretically, the effects of Medicaid may fall somewhere in between those of Medicare and managed care.

\section{B. The Medicaid Expansions}

When Medicaid commenced in 1965, coverage for pregnancy-related costs initially applied only to single mothers receiving welfare benefits, but the program expanded rapidly over the 1980s and 1990s. Eligibility for Medicaid was decoupled from welfare eligibility, and states were given the option to provide Medicaid for pregnant women under 100 percent of the federal poverty line in 1987 and then up to 185 percent of the federal poverty line in 1988 , while still receiving federal matching funds. In 1990 the federal government mandated all states to provide Medicaid to pregnant women in families earning less than 133 percent of the federal poverty line. The percentage of deliveries covered by Medicaid rose from 19.5 percent in 1985 to 35.2 percent in 1996 , while uninsured deliveries fell from 13.7 percent to 4.1 percent (Dave et al. 2011).

While these Medicaid expansions extended coverage to many previously uninsured individuals, about a quarter to a half of the increased Medicaid coverage has been attributed to crowd-out, in which individuals who would otherwise be privately insured now take up public coverage (Cutler and Gruber 
1996; Congressional Budget Office 2007). Dave et al. (2011) focus specifically on pregnant women and find a crowd-out rate of about 55 percent among those affected at the margin. Dubay and Kenney (1997) find a crowd-out rate of 45 percent for the marginal pregnant women made eligible by the expansions.

\section{Neonatal Intensive Care}

Neonatal intensive care is an important policy context for examining technology adoption during the 1980s and 1990s. It also provides an example of a technology that is particularly relevant to the population newly covered by the Medicaid expansions studied in this paper. Like many medical technologies, NICUs have significantly improved health outcomes on average (Cutler and Meara 2000); however, it is unclear if the recent NICU diffusion has been optimal from the standpoint of maximizing health benefits and minimizing costs. Early development of NICUs was concentrated in large, regional, and typically academic hospitals. In the 1980s and 1990s diffusion greatly accelerated; between 1980 and 1996, the number of NICUs almost tripled, with most of the new units located in smaller, community hospitals (Baker and Phibbs 2002). ${ }^{3}$ There is evidence that this diffusion exceeded medical need (Howell et al. 2002), that it has not been correlated with geographic variation in infant health (Goodman et al. 2001), and that it may lead to excessive utilization (Freedman 2012a). Organizations such as the March of Dimes and the American Academy of Pediatrics have repeatedly advocated for a system in which NICU resources are concentrated in larger, regional centers (Committee on Perinatal Health 1976, 1993; Committee on Fetus and Newborn 2004).

In order to understand the potential impact of insurance on providers' NICU adoption decisions, we briefly discuss the two main reasons why hospitals generally choose to open NICUs. First, for sick

\footnotetext{
${ }^{3}$ Acemoglu and Finkelstein (2008) provide evidence that Medicare incentives may have been one contributing factor in this diffusion. When Medicare transitioned to the Prospective Payment System (PPS) in 1983, it continued to reimburse hospitals for capital expenditures retrospectively at cost. Acemoglu and Finkelstein (2008) find that this policy change increased hospitals' capital expenses relative to other operating expenses and actually spurred the adoption of a range of technologies, including NICUs. While NICUs are rarely used by patients covered by Medicare, they note that this effect may represent a spillover of the policy or the fact that hospitals had wide leeway regarding which costs they attributed to Medicare. Medicare-related incentives may have partially spurred NICU diffusion during the first half of the period we study here, but unless Medicaid eligibility expansions are correlated with the state-level importance of Medicare payments, they are not likely to confound our results.
} 
infants who would have been born in a hospital regardless of whether the hospital offered a NICU, the existence of a NICU allows hospitals the opportunity to continue treating these infants instead of transferring them. ${ }^{4}$ The profitability of treating infants in a NICU may vary by insurer, but in general NICU reimbursement rates are relatively high (Horwitz 2005; online appendix).

Second, if pregnant women are more likely to choose hospitals that offer a NICU, a hospital may adopt this technology in order to increase its market share of deliveries overall. Hospitals are limited in their ability to be selected by patients on the basis of price, and this is especially true in the market for deliveries, in which almost all patients are insured. Therefore, hospitals are more likely to compete on non-price factors such as signals of quality, amenities, and service offerings, leading sometimes to a "medical arms race" (Gaynor 2006). Furthermore, it is thought that mothers are likely to return to the same hospital for subsequent care of themselves and their families if they have a positive birth experience (Friedman et al. 2002). As a result, providing a NICU may also act as a loss leader and generate downstream profits in the future. In any given year, only about 10 percent of babies receive NICU services (Schwartz et al. 2000). However, because most preterm labor is spontaneous and unpredictable, ${ }^{5}$ the existence of a NICU is likely to affect patients' choice of delivery hospital. ${ }^{6}$

Additionally, NICUs are likely to be relevant to the decision making of all mothers. Phibbs et al. (1993) find that the presence of a NICU is an important determinant in patients' hospital choice, both for privately insured and Medicaid covered deliveries. Given the overall level of unpredictability of preterm delivery, the prevalence of Medicaid eligibility is roughly similar for mothers who are more and less likely to need neonatal intensive care services for their infants. In 2001, data from the Nationwide

\footnotetext{
${ }^{4}$ Dor and Farley (1996) find that hospitals provide higher marginal cost treatment to patients with more generous payment sources, suggesting that hospitals respond to the prospect of higher reimbursement by providing more intensive treatments.

${ }^{5}$ There are a variety of documented correlates of preterm delivery such as tobacco use, nutrition, stress, and demographics, but there is in fact little understanding of what conditions and events can be used to predict and diagnose preterm labor before it occurs (Behrman and Butler 2007).

${ }^{6}$ An alternative model of demand could center on physicians and would result in similar implications. If physicians choose a hospital at which to seek admitting privileges to maximize their utility, they might care about hospital facilities to the extent that they can provide better care for their patients, minimize malpractice risk, and attract more patients who consider the delivery hospital in their physician choice. Therefore, adopting a NICU might attract more physicians and, in turn, more patients.
} 
Inpatient Sample, a nationally representative sample of hospital inpatient discharge records, show that 41.9 percent of preterm and low-birth-weight infants were covered by Medicaid and 5.3 percent lacked insurance, while the corresponding percentages for uncomplicated newborns were 37.5 percent and 5.4 percent (Russell et al. 2007).

\section{A Simple Model of Insurance Expansion and NICU Adoption}

We motivate our empirical analysis with a simple model of a Medicaid expansion and an incumbent hospital's NICU adoption, from which we generate testable empirical predictions. ${ }^{7}$ We assume that the number of deliveries a hospital performs of each insurance type is characterized by $\left(\alpha_{P}^{t}, \alpha_{M}^{t}, \alpha_{U}^{t}\right)$, where t equals 0 before Medicaid eligibility expansion and 1 after expansion, and the subscripts denote private (P), Medicaid (M), and uninsured (U) patients. Medicaid changes the overall market patient mix by allowing some of the previously uninsured to gain access to Medicaid coverage (the coverage expansion effect) and inducing some of the privately insured to switch to Medicaid (the crowd-out effect); we expect that $\alpha_{\mathrm{P}}^{1} \leq \alpha_{\mathrm{P}}^{0}, \alpha_{U}^{1} \leq \alpha_{\mathrm{U}}^{0}$ and $\alpha_{\mathrm{M}}^{1} \geq \alpha_{\mathrm{M}}^{0}$. We assume that privately insured patients are the most profitable to treat and uninsured patients are the least profitable, with profitability of Medicaid patients falling in between and depending on a state's Medicaid reimbursement generosity. Therefore, $\theta_{\mathrm{P}} \geq$ $\theta_{\mathrm{M}}>\theta_{\mathrm{U}}$, where $\theta$ denotes the profitability of treating a patient of each insurance type. We simplify our model by assuming that these profitability levels are not altered by Medicaid eligibility expansion itself. Actual data on public-private reimbursement differentials specifically for neonatal intensive care are not available to the best of our knowledge; however, we assemble data on Medicaid reimbursement to $\mathrm{OB} / \mathrm{GYNs}$ for routine deliveries and the associated prenatal care and note that these were on average 45

\footnotetext{
${ }^{7}$ Although a similar model could be used to study the reversal of adoption decisions, in practice almost no hospitals have divested themselves of NICUs during our time period. Technology abandonment is a relatively new concept in the literature and is growing in importance because of the need to understand whether comparative effectiveness research will translate to the abandonment of technology that is found to be inferior (e.g. Howard and Shen 2011).
} 
percent of private fees at the beginning of our sample in $1985 .^{8}$

An incumbent hospital decides whether to adopt a NICU if it does not already operate one, knowing that after adopting it would attract $\alpha_{P}^{t}\left(1+\varepsilon_{P}\right)$ privately insured, $\alpha_{M}^{t}\left(1+\varepsilon_{M}\right)$ Medicaid, and $\alpha_{U}^{t}\left(1+\varepsilon_{U}\right)$ uninsured patients, where $\varepsilon$ denotes how demand responds to NICU availability and is arguably positive. ${ }^{9}$ Based on evidence that demand elasticity with respect to NICU availability is positive but differs by payer (e.g., Phibbs et al. 1993), it is reasonable to assume that $\varepsilon_{\mathrm{P}} \geq \varepsilon_{\mathrm{M}} \geq \varepsilon_{\mathrm{U}}$. NICU adoption in period $t$ occurs if the increase in profitability from attracting more patients outweighs the cost of adoption, i.e.

$$
\Delta \pi^{\mathrm{t}}=\theta_{\mathrm{P}} *\left(\alpha_{\mathrm{P}}^{\mathrm{t}} \varepsilon_{\mathrm{P}}\right)+\theta_{\mathrm{M}} *\left(\alpha_{\mathrm{M}}^{\mathrm{t}} \varepsilon_{\mathrm{M}}\right)+\theta_{\mathrm{U}} *\left(\alpha_{\mathrm{U}}^{\mathrm{t}} \varepsilon_{\mathrm{U}}\right) \geq \mathrm{FC}
$$

We assume that hospitals are purely profit driven, but all model predictions hold if we instead assume an alternative objective function determined by a weighted summation of profits and patient welfare, such as the number of patients that a hospital treats (see Sloan 2000; Horwitz and Nichols 2007). We also assume that the total number of patients giving birth at a particular hospital does not change after Medicaid expansion, so the increase in the number of new Medicaid patients is equal to the total change in the private patient population and the uninsured patient population, $\alpha_{M}^{1}-\alpha_{M}^{0}=\alpha_{\mathrm{P}}^{0}-\alpha_{\mathrm{P}}^{1}+\alpha_{\mathrm{U}}^{0}-\alpha_{\mathrm{U}}^{1}$.

To understand how Medicaid eligibility expansions change hospital incentives, we compare the difference in the net gain associated with NICU adoption before $(t=0)$ and after Medicaid expansion $(t=1)$ :

$$
\begin{aligned}
& \Delta \pi^{1}-\Delta \pi^{0}=\theta_{\mathrm{P}} \varepsilon_{\mathrm{P}}\left(\alpha_{P}^{1}-\alpha_{P}^{0}\right)+\theta_{\mathrm{M}} \varepsilon_{\mathrm{M}}\left(\alpha_{M}^{1}-\alpha_{M}^{0}\right)+\theta_{\mathrm{U}} \varepsilon_{\mathrm{U}}\left(\alpha_{U}^{1}-\alpha_{U}^{0}\right) \\
= & -\left(\theta_{\mathrm{P}} \varepsilon_{\mathrm{P}}-\theta_{\mathrm{M}} \varepsilon_{\mathrm{M}}\right)\left(\alpha_{\mathrm{P}}^{0}-\alpha_{\mathrm{P}}^{1}\right)+\left(\theta_{\mathrm{M}} \varepsilon_{\mathrm{M}}-\theta_{\mathrm{U}} \varepsilon_{\mathrm{U}}\right)\left(\alpha_{\mathrm{U}}^{0}-\alpha_{\mathrm{U}}^{1}\right)
\end{aligned}
$$

The first expression on the right-hand side measures the decrease in profitability after Medicaid

\footnotetext{
${ }^{8}$ In a report commissioned by the Health Care Financing Administration (the predecessor to the Centers of Medicare and Medicaid) in the years following the initial Medicaid expansions, Serrato et al. (1991) expressed concern that access to neonatal intensive care for Medicaid-covered infants could be limited because of low reimbursement rates and prospective payment systems that did not fully capture the appropriate variation in the cost of care across diagnosis-related groups.

${ }^{9}$ One implicit assumption that we make here is that hospitals can adjust their nursery bed capacity to meet the increasing demand of pregnant women. Moreover, our results also hold if we allow $\varepsilon_{U}$ to be negative, which allows hospitals to avoid uninsured patients and attract more profitable patients (privately insured and Medicaid) after NICU adoption.
} 
expansions due to the crowd-out effect, and the second expression measures the increase in profits through the coverage expansion effect. If there is some level of crowd-out, the sign of this expression is ambiguous, suggesting that Medicaid expansion could either slow down or speed up NICU adoption. Assuming for simplicity that the profitability of treating uninsured patients is zero (i.e. $\theta_{U}=0$ ), Medicaid is likely to decelerate NICU adoption (with the above expression being negative) if the following inequality holds:

$$
\frac{\theta_{\mathrm{M}}}{\theta_{\mathrm{P}}}<\frac{\alpha_{\mathrm{P}}^{0}-\alpha_{\mathrm{P}}^{1}}{\alpha_{U}^{0}-\alpha_{U}^{1}+\alpha_{\mathrm{P}}^{0}-\alpha_{\mathrm{P}}^{1}} * \frac{\varepsilon_{\mathrm{P}}}{\varepsilon_{\mathrm{M}}}
$$

This inequality (3) is more likely to hold under the following conditions:

a. The market initial uninsurance rate, $\alpha_{U}^{0}$, is relatively small.

b. The level of crowd-out, $\left(\alpha_{P}^{0}-\alpha_{P}^{1}\right)$, is high relative to the full increase in Medicaid eligibility, $\left(\alpha_{U}^{0}-\alpha_{U}^{1}+\alpha_{P}^{0}-\alpha_{P}^{1}\right)$

c. The profitability ratio of Medicaid to private patients, $\frac{\theta_{M}}{\theta_{P}}$, is relatively small.

As suggested by this model, Medicaid expansion is likely to decelerate NICU adoption when the pre-expansion uninsurance rate is low, or conversely when the rate of insurance is high. The baseline insurance rate could also proxy for the likely level of overall crowd-out in order to incorporate the insight from condition (b). In particular, we hypothesize that in areas with lower pre-expansion insurance rates, Medicaid expansion is more likely to lead to a greater increase in overall insurance coverage, whereas markets with higher insurance coverage would likely see relatively greater numbers of privately insured individuals shift toward Medicaid coverage. The model also predicts that the relative profitability of treating patients of each payer type will play an important role in determining hospital responses to Medicaid expansion; thus we also examine how the impact of expansions and potential crowd-out differ by relative Medicaid fee generosity across states. Note that for tractability of our model, we abstract away from hospital entry, exit, and merger behaviors. We expect these behaviors to not be directly affected by the rollout of Medicaid expansions for pregnant women, and present supporting empirical evidence and 
additional analysis in Section 6.D.

\section{Data}

\section{A. Hospital Data}

We test our hypotheses regarding technology adoption using data from the American Hospital Association (AHA) Annual Survey of Hospitals from 1985 through 1996. The AHA surveys all hospitals in the U.S., collecting information on service provisions and location. Our sample includes non-Federal, acute-care, and children's hospitals. ${ }^{10}$ As in Baker and Phibbs (2002), for most of our analysis we restrict our sample to hospitals with an obstetrics unit and at least 50 births in the first year of the sample, which could be considered candidates for adopting a NICU; however, we also present some analysis without this restriction. Within the AHA data, we consider a hospital as having a NICU if it reports having beds in a neonatal intermediate or neonatal intensive care unit. ${ }^{11}$ Table 1 lists the number and fraction of hospitals with NICUs in our sample. While the total number of hospitals fell in this time period due to hospital closures and consolidation, the number of hospitals with a NICU increased from 589 to 857 between 1985 and 1996. This number amounts to an increase from 14.8 percent to 24.8 percent of sample hospitals.

\section{B. Measuring Medicaid Eligibility}

Our empirical approach exploits variation in Medicaid expansions across states and over time to estimate its impact on the likelihood that a hospital adopts a NICU. We cannot use actual year-to-year changes in a hospital's Medicaid population to identify this effect because it is likely correlated with other unmeasured local economic factors that affect NICU adoption directly. In addition, areas with greater

\footnotetext{
${ }^{10}$ We exclude federally owned hospitals (such as Veterans' hospitals), which are associated with very different payment structures and incentives relative to private hospitals. Additionally, we exclude long-term care facilities and specialty hospitals, such as cardiac hospitals, which would not be in the set of hospitals treating infants. As an exception to the specialty-care exclusion, we include children's hospitals since they typically provide neonatal intensive care.

${ }^{11}$ The AHA data are self-reported and therefore have some missing values and inconsistencies from year to year. Specifically, about 6 percent of hospital-year observations have missing values for the number of either neonatal intensive or neonatal intermediate care beds. In the Appendix, we provide details on how we address this problem by imputing missing values based on data from surrounding years.
} 
Medicaid take-up may also have more need for healthcare. To overcome these endogeneity concerns, we follow past literature on Medicaid expansions by using a measure of simulated Medicaid eligibility that only varies within a state due to legislative changes and not demographic or health trends. This methodology follows Currie and Gruber (1996), Cutler and Gruber (1996), and many subsequent studies of the impact of Medicaid expansions.

To construct a simulated eligibility measure for pregnancy-based Medicaid at the state-by-year level, we pool all women between the ages of 18 and 39 from the March Current Population Surveys covering 1985 through 1996 for each state. We then calculate what fraction of these pooled samples would be eligible for Medicaid if they were to become pregnant based on the eligibility rules for each state and year. Because we calculate this simulated measure using the same sample of women for each year, variation over time is only driven by state eligibility rules and not by changes in demographic composition. As shown in Table 1, the fraction of individuals eligible for Medicaid increased from 9.7 percent to 31.0 percent over our sample period, as states responded to Federal regulations regarding Medicaid eligibility rules.

\section{Local Market-Level Controls}

The main empirical approach described below utilizes hospital fixed effects, and therefore controls for fixed characteristics of a hospital and its local market. We also control for time-varying characteristics of a hospital's market using data from the Health Resources and Services Administration's Area Resource File (ARF), which provides annual, county-level data on population characteristics from sources such as the U.S. Census Bureau and the National Center for Health Statistics. These controls include the number of births and low-weight births, the total population, female population by age categories, and per-capita income. We use linear interpolation to fill in values when a measure is not reported for some years. We summarize the mean and standard deviations of these variables in Table 2.

Our source for state-level insurance rates is the March Supplement of the Current Population Survey (CPS). Ideally, we would measure insurance rates only among pregnant women; however, we 
cannot reliably identify a sufficient sample of pregnant women in the March CPS. We therefore use the overall rate of insurance among the population under 65 years of age, although we also find in unreported tables that the results are robust to using all women between the ages of 18 and 39.

\section{Medicaid and Private-Fee Data}

In addition to the potential patient pool's insurance composition, our analytical model suggests that reimbursement rates are also likely to be important determinants of hospital NICU adoption. Ideally, we would incorporate both hospital and physician reimbursement levels by payer. Unfortunately, comprehensive state-level data on Medicaid hospital reimbursements are not available for the time period of our study. ${ }^{12}$ However, we have obtained data used in Currie et al. (1995), which constructs a state-level measure of the ratio of Medicaid-to-private fees for total obstetric care of a vaginal birth, including both prenatal care and delivery, over the period 1979-1992. We use these fees as a proxy for the relative generosity of Medicaid versus private payers for childbirth-related services by state.

In most of our analysis below we utilize the 1985 fee ratio to stratify our sample based on relative Medicaid-to-private reimbursement generosity at the baseline of our sample. In Appendix Table 3, we also control for yearly fee data to ensure that our results are not biased by fee changes. For this analysis, we extend the Currie et al. (1995) data through 1996 and provide details on this process and the results in Appendix 2.

\section{Empirical Framework}

We operationalize our test of hospital incentives by estimating the following regression equation for hospital $h$ in county $c$ of state $s$ in year $t$, with standard errors clustered at the state level to account for correlation in the error term over time and within states:

\footnotetext{
${ }^{12}$ While there is work documenting trends in state Medicaid physician reimbursements (see Norton and Zuckerman 2000; Zuckerman et al. 2009) there are no such sources for hospital reimbursements (personal communication with Stephen Zuckerman, Urban Institute). Quinn (2008) documents Medicaid hospital-payment methods by state as of 2004 but does not provide any information on rates or trends over time.
} 


$$
N I C U_{h c s t}=\beta_{0}+\beta_{1} \text { PctElig }{ }_{s t}+\beta_{2} X_{c t}+\alpha_{t}+\gamma_{h}+\omega_{s} t+\varepsilon_{h c s t}
$$

$N I C U_{h c s t}$ is an indicator variable that equals one if a hospital offers a NICU in a given year, and PctElig $g_{s t}$ is the simulated Medicaid eligibility rate in the hospital's state and year. ${ }^{13} \alpha_{t}$ and $\gamma_{h}$ represent year and hospital fixed effects to control for general adoption trends and fixed hospital-specific characteristics, respectively. $X_{c t}$ controls for time-varying characteristics of a hospital's county extracted from the Area Resource File.

The identifying assumption of this specification is that changes in eligibility are not correlated with unobserved NICU adoption trends. Because we use simulated eligibility to ensure that the fraction eligible is not driven by demographic changes, the key assumption is that the timing of state-level legislative changes to Medicaid eligibility rules is uncorrelated with unobserved determinants of NICU adoption. To account for the fact that there may be systematic differences in adoption trends that are correlated with legislative choices, we also include state-specific linear time trends, $\omega_{s} t$. These time trends have been found to be important in previous studies of Medicaid eligibility and insurance choices (e.g. Card and Shore-Sheppard 2004; Shore-Sheppard 2008). ${ }^{14}$ As discussed in more detail in Section 6 we find that our point estimates are not substantially affected by these trends; however, we gain significant precision when we include them. ${ }^{15}$ We also conduct placebo tests that suggest that eligibility changes are not correlated with unobserved determinants of NICU provision.

In addition to estimating the overall effect of eligibility, we attempt to tease out the offsetting

\footnotetext{
${ }^{13}$ We follow papers such as Currie and Gruber (2001), DeLeire et al. (2011), and Garthwaite (2012) and estimate the reduced-form effect of simulated Medicaid eligibility. In the spirit of Currie and Gruber (1996) we have also estimated instrumental variable regressions in which we instrument for the actual fraction of CPS respondents eligible for Medicaid with the simulated fraction eligible for Medicaid. These instrumental variable results are very similar to the reduced-form results presented in the paper, and are available upon request.

${ }^{14}$ Card and Shore-Sheppard (2004) and Shore-Sheppard (2008) find that Cutler and Gruber's (1996) findings about the effects of Medicaid eligibility on insurance coverage during a similar time period as ours decrease substantially in magnitude when they include state-by-year and state-by-age dummies. Their results suggest that the model should be fully saturated in the context of insurance coverage outcomes. Our identification is driven only by state-year variation, but in the spirit of these other papers, we add state-specific linear trends to address similar concerns.

${ }^{15}$ The fact that our point estimates are not largely affected by the inclusion of state-specific time trends, but our standard errors decrease substantially, suggests that allowing for these trends only reduces the overall variability of the error term. Wolfers (2006) cautions against relying on difference in difference models in which state linear trends drastically change the conclusions; however, the fact that these trends do not greatly impact our point estimates suggests that this argument does not present a concern in our context.
} 
financial incentives by allowing the effect to vary with the baseline local socioeconomic characteristics that are likely to predict the extent to which new Medicaid coverage would be attributable to crowd-out. We do so through the following regression:

$$
\begin{aligned}
N I C U_{h c s t}=\beta_{0} & +\beta_{1} \text { PctElig } \text { st }+\beta_{2} \text { PctElig }_{s t} * \text { Ins } 85_{s}+\beta_{3} X_{c t}+\beta_{4}{\text { Ins } 85_{s} * t+\alpha_{t}+\gamma_{h}} \\
& +\omega_{s} t+\varepsilon_{h c s t}
\end{aligned}
$$

We include an interaction term between Medicaid eligibility and $I n s 85_{s}$, which measures the insurance rate in the hospital's state at its baseline in 1985 . We also add an interaction between baseline insurance and a linear time trend to account for the fact that areas with higher insurance may have differential NICU adoption trends even in the absence of changes to Medicaid. For ease of interpretation, we standardize the insurance rate so that $\beta_{2}$ reflects changes in the eligibility gradient with a one-standard-deviation change in the insurance rate from its sample mean. As shown in Table 2, the 1985 insurance rate has a mean of 82.55 percent and a standard deviation of 4.28 percent in our sample.

Ideally, we would also exploit variation in insurance rates across sub-state markets; however, no available data measures this socioeconomic variable in large enough samples below the state level for this time period. Instead, in a complementary analysis, we also use baseline 1985 county-level unemployment, an important socioeconomic determinant of insurance, ${ }^{16}$ and the baseline 1985 county-level fraction of individuals below the federal poverty line. ${ }^{17}$ We report estimates of these specifications, which show very similar patterns to our main results, in Appendix Table 1.

Finally, as discussed in our analytical model, the generosity of Medicaid reimbursement relative to private insurance payment rates is likely to impact the desire of a hospital to attract newly covered Medicaid patients, and this impact may differ in areas of low and high crowd-out. We therefore also estimate the above specifications separately for the sample of states with the most generous and the least

\footnotetext{
${ }^{16}$ Baughman (2007) finds that the effect of Medicaid and CHIP expansions on children's health insurance coverage differs by local labor-market conditions; for example, there are larger increases in overall insurance rates in markets with higher unemployment rates.

${ }^{17}$ The fraction of the population living below the federal poverty line is available in the ARF data from 1979 and 1989. We therefore use the counties' average of these two values. Results not shown here are robust to using either the 1979 value or the 1989 value.
} 
generous baseline 1985 Medicaid reimbursement rates relative to private rates. On average the low-ratio states (22 states with fee ratios less than the sample median) have a Medicaid-to-private fee ratio of 0.27 , whereas high-Medicaid-generosity states (23 states with fee ratios greater than the median) have a ratio of $0.63{ }^{18}$ Although these two samples share identical baseline state insurance rates of 83 percent, states with more generous Medicaid preferences seem to act through payment policies before being able to act through the eligibility policies enacted by the expansion. For example, high-paying states are not more generous with Medicaid eligibility at the beginning of our sample; however, they do see larger increases in eligibility over the time period (22.1 percentage points v. 19.0 percentage points). A more detailed discussion of differences in adoption patterns between these states is presented in Section 6A.

\section{Results}

\section{A. Graphical Evidence and Aggregate Analyses}

While NICU availability and Medicaid eligibility both trend upward during the study period, Figure 1 provides evidence from the raw data that increases in NICU availability are only slightly more concentrated in states with larger Medicaid expansions. This figure plots the change in the number of hospitals with a NICU per 100,000 women of childbearing age in each state against the change in the fraction of women from the fixed CPS sample that would be eligible for Medicaid under each state's eligibility rules between 1985 and 1996, along with a regression line. All non-Federal, acute-care, and children's hospitals are included in this figure in order to reflect overall changes in NICU provision at the state level.

Because this simple state-level comparison may mask important heterogeneity that might influence the extent to which Medicaid expansions affect technology adoption incentives, Figure 2 shows the same scatter plot for four groups of states based on whether their 1985 baseline Medicaid-to-privateobstetric fee ratio and their 1985 baseline insurance rate are above or below the median. This figure suggests a slightly positive relationship between eligibility and NICU provision in states that are expected

\footnotetext{
${ }^{18}$ Fee data are unavailable for Alaska, Arizona, Kentucky, Rhode Island, Texas, and Wyoming.
} 
to have low crowd-out due to low insurance rates (Panels A and C). Interestingly, in states with high insurance rates and therefore high crowd-out, the relationship is negative (Panels B and D). In particular, there is a steep negative relationship between eligibility increases and changes in NICU provision in states with high insurance rates and low fee ratios (Panel B).

Akin to these figures at the aggregate-state level, Table 3 presents state-year-level regression results with the number of hospitals operating a NICU per 100,000 women of child-bearing age as the dependent variable. Panel A considers all states, with Panels B and C focusing on states with below- and above-median Medicaid-to-private-fee ratios, respectively. Each panel presents results with and without an interaction between simulated eligibility and the 1985 state insurance rate; we also add controls progressively across columns. Consistent with the relatively flat linear fit line in Figure 1, there is no statistically significant effect of Medicaid eligibility on NICU provision when all states are considered together, regardless of the inclusion of control variables. However, our results suggest clear heterogeneity by insurance rates and fee ratios as reflected in Figure 2. For states with low fee ratios (Panel B of Table 3), the relationship between eligibility and NICU provision largely depends on the baseline insurance rate. For states with high fee ratios (Panel C of Table 3), there is no statistically significant impact of eligibility on NICU provision, regardless of the extent of crowd-out. In the next section we further explore this relationship and provide additional interpretations of the magnitudes at the hospital level.

\section{B. Hospital-Level Analyses}

We now present hospital-level estimates of Equations 4 and 5 from the sample of potential NICU adopting hospitals that operated an obstetric unit at the beginning of our sample. Panel A of Table 4 displays results for the full sample of hospitals. Columns 1 through 3 report the coefficient estimates of the eligibility variable from Equation 4 as we progressively add controls. Column 1 includes only year dummies. As we add controls for county-level characteristics in Column 2 (the number of births and number of low-birth-weight births, female population by age, and per-capita income) and then statespecific linear time trends in Column 3, the coefficient estimates are always small and statistically 
insignificant. Consistent with the raw data in Figure 1 and the state-level regressions in Table 3, we find no statistically significant effect of eligibility on NICU provision overall.

The remaining columns of Table 4 present results of Equation 5 when we allow the effect of eligibility to vary by the baseline state-level insurance rate (as a proxy for potential crowd-out). In Columns 4-7 we again progressively add controls, starting with a specification with only year dummies (Column 4), adding an interaction between baseline insurance and a linear-year term to allow areas with differing baseline insurance rates to follow different adopting trends (Column 5), adding population controls (Column 6), and adding state-specific linear time trends (Column 7). Regardless of the controls included, the eligibility main effect is not statistically different from zero, and the point estimates of the interaction terms do not vary by much. These patterns of results as controls are added suggest that Medicaid eligibility expansions are not correlated with observed determinants of NICU adoption, and are therefore less likely to be correlated with unobserved determinates; we further explore this identification assumption in Section 6.C below using two falsification tests. However, including controls and statespecific trends in Column 7 does lead to smaller standard errors, and the interaction terms now become statistically significant at the 5 percent level.

The estimates in Column 7 imply that at the mean level of state insurance, eligibility does not affect NICU provision, but that this effect does vary with the state insurance rate. To facilitate the interpretation, Figure 3 plots the estimates from Column 7 showing the effect of eligibility on NICU provision as insurance rate varies, along with the 90 percent and 95 percent confidence intervals. Below the mean insurance rate, the effect is not statistically significant at any values within two standard deviations of the mean insurance rate. In contrast, for many values above the mean level of insurance, we find the effect of eligibility on the likelihood that a hospital has a NICU to be negative and statistically significant at the 5 percent level.

We also expect that hospitals' responses to the level of crowd-out may depend on the generosity of Medicaid reimbursements relative to private reimbursements, and Figure 2 confirms this. Panels B and C of Table 4 present the results of Equations 4 and 5 separately for states with low and high Medicaid-to- 
private fee ratios. The first three columns show that there is no overall effect of eligibility on NICU provision in either sub-sample, regardless of controls. However, when we introduce the interaction between eligibility and our proxy for expected crowd-out we find that the main result that eligibility effects differ by expected crowd-out is being fully driven by low-fee-ratio states. In the low-fee-ratio sample, the interaction effect is statistically significant at the $5 \%$ level when all controls are included, mostly due to greatly increased precision once we include state-specific trends. ${ }^{19}$ These estimates for lowpaying states imply that the overall effect of Medicaid eligibility on NICU provision is statistically significant and negative for states with insurance rates more than 0.56 standard deviations above the mean. For all insurance rates below this threshold, there is no statistically significant effect. In states with high fee ratios, we find no statistically significant effect of eligibility on NICU provision, and the interaction is very small and not statistically significant. ${ }^{20}$

These results suggest that when Medicaid payment rates are low and crowd-out is expected to be most prevalent, increased eligibility has substantial negative effects on NICU provision. When Medicaid payment rates are low but crowd-out is less likely to be prevalent, the profitability of attracting this group is not largely affected, despite patient shifts from no insurance to public coverage. In states with higher Medicaid generosity relative to private insurers, eligibility has no effect on NICU provision, regardless of the expected crowd-out. This suggests that even in states in which Medicaid reimbursements are most generous and eligibility expansions are most likely to substantially increase the fraction of pregnant women covered by insurance, Medicaid payments might still be too low for hospitals to experience a change in their financial incentives for operating a NICU. ${ }^{21}$

\footnotetext{
${ }^{19}$ The interaction effect estimate is virtually unchanged by adding the insurance times year term, and the point estimate becomes slightly smaller as we include population controls. However, the standard error falls greatly once we include state-specific trends.

${ }^{20}$ In Appendix Table 2 we report results allowing the interaction between eligibility and crowd-out, conditional on reimbursement rates, to be nonlinear. We split states as into four categories as in Figure 2 and coefficient estimates confirm the raw data plotted in Figure 2. We find a large, negative, and statistically significant effect of eligibility in states with low-Medicaid-to-private fee-ratios and high baseline insurance rates. For all three other groups we find no statistically significant impact.

${ }^{21}$ We have explored whether a lack of variation in NICU diffusion in these states might drive the null results in lowcrowd-out, high-fee states where we would most expect to find positive effects. These states had lower baseline NICU provision in $1985(9 \%)$ as compared to the overall sample (14.8\%), but a similar rate of diffusion over the
} 
In order to gauge the overall magnitude of the estimated effects we conduct a counterfactual simulation of NICU diffusion in the absence of the Medicaid expansion. We first use our regression results to predict the counterfactual probability that each hospital would have operated a NICU had Medicaid eligibility remained at its 1985 level in each state. We then sum these counterfactual predictions to obtain the counterfactual number of hospitals operating a NICU by year. Finally, we compare the number of NICUs present in the data in 1996 to the counterfactual number that would have been in operation in 1996 without a Medicaid eligibility expansion. Based on the full sample regression estimate in Panel A, Column 7 of Table 4, there would have been 10 additional hospitals operating NICUs in 1996 had Medicaid expansions not occurred.

The counterfactual simulation described above covers the full sample. Because we only find statistically significant effects of eligibility on NICU provision in low-fee-ratio and high-insurance-rate states (insurance rates greater than 0.56 standard deviations above the mean), we repeat our counterfactual simulation in these areas alone based on the estimate in Panel B, Column 7. We find that in the absence of the Medicaid expansion, there would have been 9.6 additional NICUs in these low-paying, highinsurance-rate states in 1996. Interestingly, this figure is close to the counterfactual using the full sample, consistent with the fact that most of the slowed diffusion occurs in these low-paying and high insurance states. This magnitude of effect is equivalent to $7.0 \%$ of actual growth between 1985 and 1996 in low-feeratio states and to $24 \%$ of actual growth in the 9 states with low-fee ratios and insurance rates greater than 0.56 standard deviations above the mean. ${ }^{22}$ These results imply that Medicaid eligibility expansions had a large impact on NICU growth in those states where crowd-out is most important.

\section{Placebo Tests}

The identification strategy used in this paper relies on state-level changes in Medicaid eligibility

study period ( 9 percentage points as compared to 10 percentage points in the full sample), suggesting lack of variation does not drive this finding.

${ }^{22}$ Between 1985 and 1996, the number of NICUs in our analysis sample increased by 138 in low-fee-ratio states and 40 in low-fee-ratio states with insurance rates greater than 0.56 standard deviations above the mean. 
being uncorrelated with other unobserved state-level changes that might affect the likelihood of NICU adoption. Previous studies have found instances of state-level factors that could lead states to adopt new technologies at different speeds. For example, Skinner and Staiger (2005) find persistent differences in states' likelihood to adopt technologies, both medical and non-medical. If these differences are correlated with Medicaid expansion decisions and not captured by our state-specific linear time trends, our estimates would be biased. In addition to general tastes for technology, there may be other policy changes that affect technology adoption, and our results would be confounded if such changes coincided with Medicaid eligibility policy. ${ }^{23}$

We conduct several additional tests of our identification assumption beyond the above discussion of successively adding controls. First, we test whether future Medicaid eligibility changes impact current NICU adoption. If we were to find that future changes to Medicaid eligibility are correlated with current NICU provision, it would suggest that changes in NICU provision occurred prior to the actual rollout of eligibility changes. This pattern would shed doubt on the assumption that eligibility expansions are independent of pre-existing NICU adoption trends. We test this in Columns 1, 3, and 5 of Table 5 by adding a two-year lead of eligibility and its interaction with the baseline insurance. ${ }^{24}$ In the full sample and the low-fee-ratio sample, we find no statistically significant lead effect of Medicaid eligibility and its interaction with the baseline insurance rate. In the high-fee-ratio states we do find a negative and statistically significant main effect of future Medicaid eligibility, suggesting that these states may have seen slowing NICU adoption concurrent with eligibility increases; overall, however, this placebo test

\footnotetext{
${ }^{23}$ The period that we study, particularly the early 1990s (Ku and Coughlin 1995; Coughlin et al. 2000), also coincides with expansions of the Disproportionate Share Program (DSH), which allowed states to receive matching federal funds in order to distribute additional payments to hospitals treating a disproportionate number of indigent patients. Hospital-level data on DSH payments were not made available until after 1998, and the only reliable data available for our study period are state-level aggregated DSH hospital payments for 1993 from Ku and Coughlin (1995) and Coughlin et al. (2000). We find that our results are consistent if we focus on just the pre-1990 period, when states were reluctant to implement DSH programs. We also conduct additional analysis by incorporating DSH payment to adjust relative fee-ratio across states; the results are similar and available upon request.

${ }^{24}$ Many states change eligibility multiple times during our study period, often in consecutive years. For example, if we consider policies that change simulated eligibility by one percentage point or more in a given year, one quarter of these changes are followed by another change of one percentage point or more in the next year, often because Medicaid policy changes are designed as phased expansions. In order to avoid estimating lead effects that are simply picking up contemporaneous effects of consecutive changes, we have chosen to include only two-year leads in these regressions. Similarly, we include two-year lagged effects in subsequent analysis.
} 
supports our identifying assumptions. In unreported results, we also find that these results are not sensitive to which controls are included; lead effects are small and statistically insignificant in all cases.

In Columns 2, 4, and 6 of Table 5, we also include two-year lags of eligibility and its interaction with 1985 insurance rate in order to better trace out the timing of responses to eligibility changes. These results suggest that in the full sample and in low-fee-ratio states, there are additional lagged effects of eligibility when crowd-out is prominent. In high-fee-ratio states where we may have expected some positive effects to take place by allowing for lagged effects, given the likely planning and construction time involved in opening a NICU, we still find no statistically significant effects.

To further ensure that tastes for technology and other concurrent technology-related policies do not confound our results, we present an additional placebo test by examining the impact of Medicaid eligibility expansions for pregnant women on hospitals' adoption of two cardiac-care-related technologies, catheterization labs and open-heart surgery. We choose these two technologies because they represent important investment decisions for hospitals. Additionally, these two technologies diffused rapidly during our study period, with the percent of sample hospitals providing catheterization labs increasing from 19.7 to 34.2 and the percent providing open-heart surgery increasing from 12.7 to 19.4.

Because the adoption of such technologies should not be directly affected by Medicaid expansion for pregnant women, we would not expect to see Medicaid eligibility significantly impact the adoption of cardiac-care-related technologies. ${ }^{25}$ Specifically, we run our main specifications in Equations 4 and 5 using dummy variables for the provision of catheterization labs and open-heart surgery as the dependent variables. ${ }^{26}$ The estimation results, reported in Table 6, support that the main findings of this paper are not driven by unobserved heterogeneity at the state-year level that is common to the adoption of NICUs and

\footnotetext{
${ }^{25}$ If hospitals face capital constraints and respond to Medicaid expansions for pregnant women by investing in NICUs, they might delay their adoption of other technologies, such as those related to cardiac care. Nevertheless, even in such cases, we expect the impact on cardiac care to be opposite to that of NICUs and to be much less pronounced.

${ }^{26}$ In results available upon request, these estimates are also not sensitive to which controls are included.
} 
cardiac-care-related treatments. ${ }^{27}$

\section{Hospital Entry, Exit, and Merger}

In this section we examine whether Medicaid eligibility expansions could alter other hospital decisions, beyond just NICU adoption. In particular, changes in the profitability of treating a large patient pool through Medicaid expansions might have an impact on hospitals' entry, exit, and merger decisions. Whether Medicaid expansions impact entry, exit, and merger decisions is an interesting question on its own, as is whether Medicaid expansions could be affecting NICU adoption through these decisions (compositional effects). Furthermore, our within hospital estimates could themselves be biased if sample attrition associated with market participation is directly related to Medicaid expansions. Below we present a series of findings to address these questions.

We first present some patterns in the data regarding entry, exit, and merger, which suggest that these hospital decisions are not likely to have a large impact on NICU provision. While our main analysis focuses on a sample of incumbent potential NICU adopters, in order to get a broader sense of entry, exit, and merger, we now consider all non-federal, general, acute-care hospitals and children's hospitals, which number between 5,000 and 5,600 hospitals per year. We find that entry is very rare during our study period. Over our twelve-year period, only 139 new hospitals enter, of which 9 operate a NICU upon opening and 24 eventually open a NICU by $1996 .{ }^{28}$ At the state-year level, $87 \%$ out of a total of 612 cells have zero entrances. Exit is more common during this time period with 605 hospital closures, though more than $56 \%$ of state-year cells have zero exits. Additionally, only $21(3.5 \%)$ of these hospitals operate a NICU at the time of closure.

This time period also witnessed increasing hospital merger activity; however, almost $80 \%$ of the

\footnotetext{
27 All the other coefficients are small and not statistically significant, with one exception of a positive main effect of Medicaid eligibility on catheterization labs in high-fee-ratio states. The fact that this positive effect only occurs to labs in high-fee-ratio states, where we do not find any effect of Medicaid eligibility, does not suggest large concern about the identification strategy given our other tests.

${ }^{28}$ We identify entry and exit using data obtained from the NBER and created by Sujoy Chakravarty of Rutgers University by combining information from the annual AHA appendices on reasons for the addition and deletion of hospitals and additional information from web searches.
} 
state-year cells have zero mergers. Among a total of 179 merger events between two or more general acute-care hospitals, ${ }^{29} 74$ involve at least one hospital operating a NICU, and almost all of these (64) involve exactly one hospital operating a NICU at the time of the merger. Additionally, almost all of the hospitals resulting from these mergers involving NICUs also operate a NICU after the merger (66). In other words, like entry and exit, merger changes the set of hospitals in the market, but has little effect on the number of NICUs in operation. In light of the discussion above, we do not expect that Medicaid expansions would have a large impact on NICU adoption through hospitals entering, exiting, or merging.

We strengthen this conclusion by comparing our state- and hospital-level results. Note that the disaggregate hospital-level regressions focus on a within-hospital effect, which is identified by incumbent hospitals that switch their NICU provision during the sample period. The aggregate state-level regressions represent the overall effect (including any compositional effect and the within effect) of eligibility on the number of total NICUs at the state level. If it were the case that there is a large compositional effect (for example, Medicaid expansions cause many hospitals with NICUs to enter the market), the aggregate analysis would yield different results from the disaggregate analysis. We find that our hospital-level results (reported in Table 4) are consistent with the aggregate, state-level estimates based on the broader sample of all acute-care and children's hospitals (presented in Table 3). ${ }^{30}$ In fact, the magnitudes of the implied effects are very similar when compared to the means of the respective dependent variables, which confirms that any compositional effects must be very small. ${ }^{31}$

We also provide empirical tests to show that market participation activities themselves,

\footnotetext{
${ }^{29}$ Mergers are also gathered from the annual AHA appendices on ID additions and deletions, which catalog cases in which IDs are changed due to mergers. Typically, a merger results in the deletion of the IDs associated with the merging hospitals, and in the addition of a new ID for the resulting merged hospital. We consider here only mergers in which at least two of the merging hospitals were general acute-care hospitals. If a general acute-care hospital merges with a specialty hospital, such as a psychiatric hospital, the result is almost always a general acute-care hospital. We therefore do not consider these types of mergers since they do not impact the number of general acutecare hospitals that might operate NICUs.

${ }^{30}$ This comparison also relates to another concern that our hospital-level analysis could be problematic due to the sample "at risk" of adopting a NICU changing over time, since only hospitals that have not yet adopted can consider adoption. The similarity between the state-level estimates that simply consider the overall number of NICUs over time and the hospital fixed effect results suggests this is not impacting our estimates.

${ }^{31}$ For example, if we consider a 21-percentage-point increase in Medicaid eligibility for low-fee-ratio states that are one standard deviation above the mean insurance rate, the estimates imply an effect equivalent to $8.3 \%$ of the sample mean dependent variable at the hospital level and a 9.7\% effect at the state level.
} 
particularly exits, are not directly affected by Medicaid expansions. While the discussion above suggests entry, exit, and merger are not channels by which Medicaid expansions are likely to affect NICU provision, it is an interesting question by itself how these expansions impact hospitals' market participation decisions. Because of the significant number of zeroes in the entry and merger data, we focus only on Medicaid eligibility's effect on exit. ${ }^{32}$ We regress the number of exits per 100,000 women of childbearing age on eligibility and its interaction with baseline insurance following the specification that we used in Column 7 of Table 3. We present results in Table 7 for the full sample and the two feeratio subsamples in Column 1. These results suggest that Medicaid expansions do not have a direct impact on exit for the full sample or for the two subsamples based on relative fee ratios.

These results also suggest that since market participation decisions are not correlated with Medicaid expansions, changes to the composition of our hospital-level analysis sample are not likely to contaminate our identification of the impact of Medicaid expansions using variation in NICU provision within hospitals; however, we also provide direct tests to examine attrition from our analysis sample of hospitals with an active obstetric unit in 1985. By definition, this sample does not allow for entry but is impacted by exit and merger. Our main hospital-level analysis sample starts with 3,993 hospitals in 1985. By the end of our study period, 543 hospitals have left our sample: 254 are attributed to pure exit and 232 to merger. In this hospital-level analysis, most mergers appear as if two hospitals exit from the sample. The remaining sample attrition is due to other events such as ID or name changes and de-mergers. 105 of these 543 hospitals are operating NICUs when they leave our analysis sample, most of which are being operated by merging hospitals that we no longer track after merger.

To ensure that changes in our hospital-level sample are not endogenous to Medicaid expansions, we regress the number of "exits" per 100,000 women of childbearing age on our policy variables and

\footnotetext{
${ }^{32}$ We have also estimate state fixed effect conditional logit models for entry, exit, and merger. To be more specific, in the case of entry, we define a dummy variable to represent whether a state-year observation has experienced any entrances. We construct similar dummies for exit and merger. We find consistent results for the full sample and the two subsamples (based on fee-ratios) that Medicaid expansions have no statistically significant effect on the likelihood of a state-year experiencing entry, exit, or merger.
} 
controls at the state-year level. Unlike in the above analysis where we considered only pure exits (closures) from the full sample of hospitals (Column 1 of Table 7), here exit is simply defined as hospitals leaving our main analysis sample. These results are presented in Columns 2 of Table 7. We find that Medicaid expansions have no statistically significant effect on sample attrition, and the point estimates are small as well. In Column 3 of Table 7 we also find that the Medicaid expansions have no effect on the number of hospitals with a NICU in operation leaving the sample each year. These results collectively suggest that sample attrition is unlikely to bias our main estimates.

Finally, to show that different treatments of entry, exit, and merger do not lead to different results, we present results for various versions of our hospital-level sample in Table 8. Column 1 repeats the results from our main analysis sample, which does not allow for entry but allows for exit. Column 2 shows that coefficient estimates are very similar if we exclude exiting hospitals by only considering the subsample of these hospitals that remain in the data for all 12 years. Column 3 replicates our hospital analysis for the sample of all general acute-care and children's hospitals, and Column 4 considers the subset of these hospitals in the sample for all 12 years, thus excluding entry and exit. All of these different samples yield consistent results. The magnitude of the interaction effect is smaller in Column 3, which is unsurprising since the sample mean of NICU provision is smaller for this sample of all hospitals (17.9\% as compared to $20 \%$ in our baseline sample of hospitals that already operated an obstetrics unit at baseline). Taken together, our results imply that entry, exit, and merger are not likely to impact our hospital-level estimates. In addition, we find no evidence of a large sample compositional effect of Medicaid expansions.

\section{E. Additional Robustness Tests}

Table 8 presents some additional robustness tests for the main results. In Column 5 we present results of our main model weighted by the number of births delivered by each hospital in 1985 . This allows us to interpret the results as the effect of Medicaid eligibility on the fraction of infants born in hospitals with NICUs rather than the effect for the average hospital. If anything, we find stronger results 
when weighting by births. Column 6 considers that conventional wisdom holds that hospitals are not likely to close NICUs once they have been adopted, and therefore cases in the data in which hospitals reported having a NICU one year but not a following year may be due to reporting errors. We therefore redefine our NICU indicator by assuming that once a hospital offers a NICU, it continues to do so in all subsequent years. The results are very similar to our main findings.

\section{F. Heterogeneity}

Table 9 explores heterogeneity by hospital characteristics. Columns 1 through 3 study ownership type; here, we estimate our main specifications for government-owned, nonprofit, and for-profit hospitals. We might expect for-profit hospitals to be more responsive to financial incentives in making technology adoption decisions. However, the results suggest that our main findings are driven by nonprofit hospitals. A caveat of these results is that the for-profit sample size is much smaller, leading to much larger standard errors and potentially to insignificant results due to a lack of precision. We also find smaller and not statistically significant coefficients for government-owned hospitals, which is not surprising since nonFederal but government-owned hospitals tend to be smaller and less financially capable of operating NICUs.

Table 9 also explores heterogeneity by two different measures of a hospital market's competitive environment. First, because hospitals often invest in NICUs in order to compete for births, we might expect Medicaid expansion related adoption incentives to interact with local market competition. Second, the marginal benefit of adoption is likely to vary with the number of existing NICUs; therefore, hospitals may respond to Medicaid expansions differently based on how many other hospitals in their market have already adopted a NICU.

In Columns 4 through 6 of Table 9, we separately estimate our main specification for subsamples stratified by level of competition as measured by the Herfindahl-Hirschman index (HHI) of 
births in a county. ${ }^{33}$ In Columns 7 through 9, we stratify the sample by the predicted fraction of other hospitals in the county already operating a NICU. ${ }^{34}$ Both sets of regressions lead to similar patterns of results. We find the results are consistent with our main findings in monopoly markets (Columns 4 and $7)^{35}$ and in competitive markets, either measured by a low HHI (Column 6) or by the fraction of competing hospitals already operating a NICU (Column 9). However, we find no evidence that Medicaid expansions slow NICU adoptions in markets with intermediate HHIs or markets with a smaller fraction of competing hospitals operating NICUs. This finding is in line with hospitals in these markets facing a higher marginal benefit of adopting a NICU due to strategic motives, such as preemption incentives. Negative financial incentives associated with Medicaid expansions and crowd-out might not be strong enough to change adoption behavior in these markets.

\section{Further Implications: NICU Adoption and Infant Health}

Thus far, our results have suggested that Medicaid eligibility expansions decelerate NICU adoption in regions with high expected levels of crowd-out and relatively less generous Medicaid payments. Here we provide some suggestive tests of the ways in which this supply-side response to public health insurance expansion may have impacted health outcomes. In prior research examining the causal impact of insurance system changes on NICU adoption, Baker and Phibbs (2002) find that managed-care penetration slowed the adoption of mid-level NICUs from 1980 to 1996, a similar time period to that of our analysis. They also find that high-risk infants born in hospitals newer, mid-level NICUs have higher mortality rates than those born in more established, high-level facilities and provide suggestive evidence

\footnotetext{
${ }^{33}$ We use the number of births reported by each hospital in each year from the AHA data to construct county-level market shares and then use these market shares to construct a county-level HHI in the market for births. In unreported results we also construct a measure of HHI based on all hospital admissions and find similar results. ${ }^{34} \mathrm{We}$ do not use the actual fraction of other hospitals operating a NICU to avoid the potential bias caused by splitting the sample by realized values of the dependent variable. Instead we use a regression of NICU provision on all of the variables in our interaction effect model to predict the probability that each hospital operates a NICU in a given year. For each hospital we then sum the probabilities associated with all other hospitals in the focal hospital's county. This represents the predicted number of other hospitals in the county operating a NICU. We then divide by the number of other hospitals to obtain the predicted fraction of other hospitals operating a NICU.

${ }^{35}$ The samples in Columns 4 and 7 are slightly different because a hospital that performs all of a county's births can have a birth HHI of 10,000 , even if it is not the only hospital present in the county.
} 
that managed-care penetration itself decreased infant mortality. Therefore, they conclude that managedcare-induced deceleration in NICU diffusion is likely to be health improving. While Freedman (2012b) finds that level of care at the delivery hospital does not impact mortality when accounting for unobserved sources of hospital selection, on average it appears that decreasing the number of hospitals offering NICUs would likely be cost saving and at least not harmful to health. Given past concerns about excessive diffusion of mid-level NICUs by organizations such as the American Academy of Pediatrics (Committee on Perinatal Health 1993), the slowed diffusion may not be expected to have a negative impact on health.

However, average effects may mask important heterogeneity across demographic subgroups. There may be some groups of the population without sufficient access to necessary care, and the effect of Medicaid expansion on hospitals' decisions to adopt NICUs may be particularly important for these groups. For example, while Currie and $\operatorname{Gruber}(1997,2001)$ find that Medicaid expansions have little effect on the mortality rates of infants born to teen or high-school-dropout mothers, they do find decreased infant mortality among those mothers whose nearest hospital operates a NICU. If Medicaid expansion changes the prevalence of NICUs, it could have health implications for the infants born to women who gain coverage from the expansion. Additionally, Aizer, Lleras-Muney, and Stabile (2005) find that poorer women are more likely to give birth in lower-quality hospitals and that increases in the generosity of their insurance lead to increased access to higher-quality hospitals.

While poor, teen, and high-school-dropout mothers are likely to be less prevalent in these highcrowd-out areas as proxied by higher insurance rates, access to neonatal intensive care may be particularly relevant for some groups of women impacted by the expansion. If slowed diffusion in high crowd-out states decreases access to neonatal intensive care for these groups of infants, there may be important health consequences.

We provide some suggestive evidence on whether changes in NICU provision induced by Medicaid expansion have any impact on infant mortality rates. For this analysis we utilize the NCHS's Vital Statistics Birth Cohort Linked Birth/Infant Death Data, which provides demographic and health 
characteristics from all US birth certificates and links to infant death certificates for any deaths within a year of the birth. These data are not available for 1992-1994, so for this analysis we use births occurring during the periods 1985-1991 and 1995-1996. Because we are interested in the ways in which Medicaid expansion affects mortality through neonatal intensive care, we restrict our sample to low-birth-weight infants to consider infants most likely to need this type of care. ${ }^{36}$ To match the infant mortality rates with the population controls and crowd-out proxies we utilize in our main analysis, we collapse vital statistics data to the county-year level. ${ }^{37}$

Our analysis examines whether Medicaid eligibility expansions had differential impacts on lowbirth-weight mortality rates in the areas where we find differential impacts on NICU adoption. Our strategy is to regress county-level low-birth-weight mortality rates on our measures of Medicaid eligibility and its interaction with our crowd-out proxy. As in our main analysis, we also separate the sample by levels of Medicaid-to-private fee ratio. In addition to the population controls included in the NICU adoption models, we also include county-level averages of individual-level infant characteristics including mother's age, race, and education; sex of the infant; and multiple birth status. These models also include county and year fixed effects along with state-specific linear time trends.

The results reported in Table 10, and Column 1 of Panel A show that, consistent with Currie and Gruber's $(1997,2001)$ findings, Medicaid eligibility has a small and negative but not statistically significant impact on mortality overall. We also find no evidence that mortality effects vary with insurance rate, either in low- or high-fee states. In unreported tables, we find similar results when restricting the sample to infants born to teenage and high-school-dropout mothers. While these results are somewhat imprecisely estimated, ${ }^{38}$ they suggest that the marginal NICUs deterred by Medicaid

\footnotetext{
${ }^{36}$ While Currie and Gruber's work shows that decreasing mortality rates are associated with Medicaid expansion, it also finds decreasing rates of low birth-weight and increasing use of prenatal-care procedures that are not likely to be connected to NICU access.

${ }^{37}$ Note that our sample is restricted to counties with populations greater than 250,000 , as the publicly available vital statistics data only include county identifiers for these larger counties.

${ }^{38}$ In low-fee-ratio states, the $95 \%$ confidence interval on the interaction term coefficient implies that a 21 percentage-point increase in eligibility would decrease mortality rates by between -0.83 and 0.36 percentage points when the insurance rate is one standard deviation above the mean.
} 
expansions in certain low-paying areas do not have a detectable impact on mortality outcomes.

\section{Discussion and Policy Implications}

Our understanding of the ways in which large-scale insurance expansion affects technology adoption is informed mainly by empirical examples from Medicare and managed care. We contend that Medicaid may have an impact that is theoretically different and may fall somewhere between these prior two cases, and that this effect is important to investigate, especially as Medicaid is expanding substantially for adults under the ACA. Using the case of hospital NICU technology during the last period of large Medicaid expansions involving an adult population (pregnancy-related eligibility during the 1980s and 1990s), we contribute to the literature by providing the first analysis of Medicaid expansions and technology adoption. We draw our testable hypotheses from an analytical model in which we discuss the opposing incentives created for incumbent hospitals by Medicaid expansions, and pay close attention to how the predicted behavioral responses rely on reimbursement levels and the degree of expected private insurance crowd-out.

Despite the fact that NICU technology diffused rapidly during these Medicaid expansions, we find that on average Medicaid expansions had a negative but not statistically significant impact on hospitals' decisions to adopt NICUs. To understand the extent to which crowd-out affects hospitals' responses to the expansion, we examine heterogeneity by a proxy for crowd-out (baseline insurance). In high-insurance states where more new Medicaid patients are likely to have been privately insured at baseline, Medicaid eligibility expansions decrease the likelihood that a hospital has a NICU. This finding is particularly notable in states where Medicaid reimbursement rates are low relative to private rates. In low-insurance states where we might expect Medicaid expansion to most significantly increase the level of insurance coverage, we do not find large impacts on NICU provision. Even where Medicaid payment rates are relatively high, we do not find evidence that hospitals pursue NICU adoption. Note that even in states with higher Medicaid payment rates, Medicaid rates are still only 63 percent of private rates on average. We also show that Medicaid expansions do not impact hospitals' market participation decisions 
and that our results are similar when estimated at the state-level, suggesting Medicaid eligibility's effect on NICU adoption is primarily driven by incumbent hospitals.

Taken together, our results portray the effect of Medicaid expansion as having slowed the adoption of technology, which contrasts with the evidence on the Medicare program. One factor our results point to as possibly responsible for this difference is that Medicaid payment rates are less generous than Medicare payments. Therefore hospital responses to Medicaid expansions have more in common with responses to the rollout of managed-care insurance than to previous large increases in the number of individuals covered by Medicare insurance. In the context of neonatal intensive care, the fact that Medicaid expansions slowed diffusion in high-insurance areas may imply that these eligibility changes actually curtailed expensive investments that are likely not to be health improving. On the other hand, in low-insurance areas, where we might expect access to necessary care to be the most limited, we do not find that providing additional public coverage to low-income pregnant women increased the availability of neonatal intensive care. This may be the population for which additional care availability has the most scope for improving health. Further exploring this heterogeneity is an important avenue for future research.

The literature on technology adoption and health care costs recognizes the difficult tradeoff between medical advances and health (e.g. Cutler 2005). In this context, there would be concern that implications of Medicaid expansions for NICU technology might affect infant health through low-birthweight infant mortality rates. Using an identification strategy similar to the one we use for testing technology adoption outcomes, we provide some suggestive evidence on health impacts by using data from the linked infant mortality files for 1985-1996. We do not find any evidence of health impacts, even in cases of states with low fees and high insurance, where our main analysis indicated that NICU adoption was slowed by Medicaid expansions. This finding is not surprising, as it is likely that although NICU technology is undoubtedly lifesaving, the marginal NICU that was deterred from adoption is likely not a large determinant of infant health given the increasingly dense availability of NICUs regionally during this time period. 
Our findings also have important implications for the insurance expansions through the ACA. While it may be difficult to determine which well-defined technologies specifically appeal to the newly insured populations, such as neonatal intensive care in the case of pregnant women, our results are informative about potential heterogeneity of supply-side responses to different types of insurance expansions. 


\section{References}

Acemoglu, D., Cutler, D., Finkelstein, A., Linn, J., 2006. Did Medicare Induce Pharmaceutical Innovation? The American Economic Review 96, 103-107.

Acemoglu, D., Finkelstein, A., 2008. Input and Technology Choices in Regulated Industries: Evidence from the Health Care Sector. Journal of Political Economy 116, 837-880.

Aizer, A., Lleras-Muney, A., Stabile, M., 2005. Access to Care, Provider Choice, and the Infant Health Gradient. The American Economic Review 95, 248-252.

Baker, L.C., 2001. Managed Care and Technology Adoption in Health Care: Evidence from Magnetic Resonance Imaging. Journal of Health Economics 20, 395-421.

Baker, L.C., Phibbs, C.S., 2002. Managed Care, Technology Adoption, and Health Care: The Adoption of Neonatal Intensive Care. The RAND Journal of Economics 33, 524-548.

Baughman, R., 2007. Differential Impacts of Public Health Insurance Expansions at the Local Level. International Journal of Health Care Finance and Economics 7, 1-22.

Behrman, R.E., Butler, A.S. (Eds.), 2007. Preterm Birth: Causes, Consequences, and Prevention. The National Academies Press, Washington, D.C.

Blume-Kohout, M.E., Sood, N., 2008. The Impact of Medicare Part D on Pharmaceutical R\&D. National Bureau of Economic Research Working Paper Series No. 13857.

Card, D., Shore-Sheppard L.D., 2004. Using Discontinuous Eligibility Rules to Identify the Effects of the Federal Medicaid Expansions on Low-Income Children. The Review of Economics and Statistics 86(3), 752-766.

Chandra, A., Skinner, J.S., 2011. Technology Growth and Expenditure Growth in Health Care. National Bureau of Economic Research Working Paper Series No. 16953.

Chou, S., Liu, J., Hammitt, J.K., 2004. National Health Insurance and Technology Adoption: Evidence from Taiwan. Contemporary Economic Policy 22, 26-38.

Clemens, J.P., 2012. The Effect of U.S. Health Insurance Expansions on Medical Innovation. SSRN eLibrary.

Committee on Fetus and Newborn, 2004. Levels of Neonatal Care. Pediatrics 114, 1341-1347.

Committee on Perinatal Health, 1976. Toward Improving the Outcome of Pregnancy: Recommendations for the Regional Development of Maternal and Perinatal Health. March of Dimes, White Plains, NY.

Committee on Perinatal Health, 1993. Toward Improving the Outcome of Pregnancy: The 90s and Beyond. March of Dimes, White Plains, NY.

Congressional Budget Office, 2007. The State Children's Health Insurance Program. Washington, D.C.

Congressional Budget Office, 2014. Insurance Coverage Provisions of the Affordable Care Act - CBO's February 2014 Baseline. Washington, D.C. http:/www.cbo.gov/sites/default/files/cbofiles/attachments/43900-2014-02-ACAtables.pdf

Coughlin, T.A., Ku L., Kim J., 2000. Reforming the Medicaid Disproportionate Share Hospital Program. Health Care Finance Review 22(2), 137-157.

Currie, J., Gruber, J., 1996. Health Insurance Eligibility, Utilization of Medical Care, and Child Health. The Quarterly Journal of Economics 111, 431-466.

Currie, J., Gruber, J., 1997. The Technology of Birth: Health Insurance, Medical Interventions, and Infant Health. National Bureau of Economic Research Working Paper Series No. 5985.

Currie, J., Gruber, J., 2001. Public Health Insurance and Medical Treatment: the Equalizing Impact of the Medicaid Expansions. Journal of Public Economics 82, 63-89.

Currie, J., Gruber, J., Fischer, M., 1995. Physician Payments and Infant Mortality: Evidence from Medicaid Fee Policy. The American Economic Review 85, 106-111.

Cutler, D.M., 2005. Your Money or Your Life: Strong Medicine for America's Health Care System, 1st ed. Oxford University Press, New York.

Cutler, D.M., Gruber, J., 1996. Does Public Insurance Crowd Out Private Insurance? The Quarterly Journal of Economics 111,391-430. 
Cutler, D.M., Meara, E., 2000. The Technology of Birth: Is It Worth It?, in: Frontiers in Health Policy Research, Volume 3, NBER Chapters. National Bureau of Economic Research, Inc, pp. 33-68.

Dave, D.M., Decker, S.L., Kaestner, R., Simon, K.I., 2011. The Effect of Medicaid Expansions on the Health Insurance Coverage of Pregnant Women: An Analysis Using Deliveries. Inquiry 47, 315 330.

Decker, S.L., 2007. Medicaid Physician Fees and the Quality of Medical Care of Medicaid Patients in the USA. Review of Economics of the Household 5, 95-112.

Decker, S.L., 2009. Changes in Medicaid Physician Fees and Patterns of Ambulatory Care. Inquiry 46, 291-304.

DeLeire, T., Leonard M.L, Simon, K.I., 2011. Medicaid Expansions and Fertility in the United States. Demography 48(2), 725-747.

DeNavas-Walt, C., Proctor, B.D., Smith, J.C., 2012. Income, Poverty, and Health Insurance Coverage in the United States: 2011. U.S. Census Bureau.

Dor, A., Farley, D.E., 1996. Payment Source and the Cost of Hospital Care: Evidence from a Multiproduct Cost Function with Multiple Payers. Journal of Health Economics 15, 1-21.

Dubay, L., Kenney, G., 1997. Peer Review: Did Medicaid Expansions for Pregnant Women Crowd Out Private Coverage? Health Affairs 16, 185-193.

Finkelstein, A., 2004. Static and Dynamic Effects of Health Policy: Evidence from the Vaccine Industry. The Quarterly Journal of Economics 119, 527-564.

Finkelstein, A., 2007. The Aggregate Effects of Health Insurance: Evidence from the Introduction of Medicare. The Quarterly Journal of Economics 122, 1 -37.

Freedman, S., 2012a. Capacity and Utilization in Health Care: The Effect of Empty Beds on Neonatal Intensive Care Admission.

Freedman, S., 2012b. The Effect of Deregionalization on Health Outcomes: Evidence from Neonatal Intensive Care.

Friedman, B., Devers, K.J., Steiner, C.A., Fox, S., Steven H., 2002. The Use of Expensive Health Technologies in the Era of Managed Care: The Remarkable Case of Neonatal Intensive Care. Journal of Health Politics, Policy and Law 27, 441-464.

Fuchs, V.R., 1996. Economics, Values, and Health Care Reform. American Economic Review 86, 1-24.

Garthwaite, C.L., 2012. The Doctor Might See You Now: The Supply Side of Public Health Insurance Expansions. American Economic Journal: Economic Policy 4(3): 190-217.

Goodman, D.C., Fisher, E.S., Little, G.A., Stukel, T.A., Chang, C., 2001. Are Neonatal Intensive Care Resources Located According to Need? Regional Variation in Neonatologists, Beds, and Low Birth Weight Newborns. Pediatrics 108, 426-431.

Gruber, J., 2008. Covering the Uninsured in the United States. Journal of Economic Literature 46, 571606.

Horwitz, J.R., 2005. Making Profits and Providing Care: Comparing Nonprofit, For-Profit, and Government Hospitals. Health Affairs 24, 790-801.

Horwitz, J.R., Nichols, A., 2007. What Do Nonprofits Maximize? Nonprofit Hospital Service Provision and Market Ownership Mix. National Bureau of Economic Research Working Paper Series No. 13246.

Howard, D.H., Shen, Y.-C., 2011. Comparative Effectiveness Research, COURAGE, and Technological Abandonment (Working Paper No. 17371). National Bureau of Economic Research.

Howell, E.M., Richardson, D., Ginsburg, P., Foot, B., 2002. Deregionalization of Neonatal Intensive Care in Urban Areas. American Journal of Public Health 92, 119-124.

Hult, K.J., Philipson, T.J., 2012. Health Care Reforms and the Value of Future Public Liabilities (Working Paper No. 18571). National Bureau of Economic Research.

Kaiser, 2012. Medicaid \& CHIP [WWW Document]. statehealthfacts.org. URL http://www.statehealthfacts.org/comparecat.jsp?cat=4\&rgn=6\&rgn=1

$\mathrm{Ku}, \mathrm{L}$, Coughlin T.A., 1995. Medicaid Disproportionate Share and Other Special Financing Programs. Health Care Financing Review 16(3), 27-54. 
Newhouse, J.P., 1992. Medical Care Costs: How Much Welfare Loss? Journal of Economic Perspectives $6,3-21$.

Norton, S., Zuckerman, S., 2000. Trends in Medicaid Physician Fees, 1993-1998. Health Affairs 19, 222232.

Phibbs, C.S., Mark, D.H., Luft, H.S., Peltzman-Rennie, D.J., Garnick, D.W., Lichtenberg, E., McPhee, S.J., 1993. Choice of Hospital for Delivery: a Comparison of High-Risk and Low-Risk Women. Health Services Research 28, 201-222.

Quinn, K., 2008. New Directions in Medicaid Payment for Hospital Care. Health Affairs 27, 269-280.

Russell, R.B., Green, N.S., Steiner, C.A., Meikle, S., Howse, J.L., Poschman, K., Dias, T., Potetz, L., Davidoff, M.J., Damus, K., Petrini, J.R., 2007. Cost of Hospitalization for Preterm and Low Birth Weight Infants in the United States. Pediatrics 120, e1-9.

Schwartz, A., Colby, D.C., Reisinger, A.L., 1991. Variation in Medicaid Physician Fees. Health Affairs, Spring, 131-139.

Schwartz, R.M., Kellogg, R., Muri, J.H., 2000. Specialty Newborn Care: Trends and Issues. Journal of Perinatology 20, 520-529.

Serrato, C.A., McCormick, M., Richardson, D., Schore, J., Thornton, C., 1991. Medicaid: Neonatal Intensive Care Unit Costs. Mathematica Policy Research, Inc.

Shore-Sheppard, L.D., 2008. Stemming the Tide? The Effect of Expanding Medicaid Eligibility on Health Insurance Coverage. The B.E. Journal of Economic Analysis and Policy 8(2), 1-35.Skinner, J., Staiger, D., 2005. Technology Adoption From Hybrid Corn to Beta Blockers. National Bureau of Economic Research Working Paper Series No. 11251.

Sloan, F.A., 2000. Not-for-Profit Ownership and Hospital Behavior, in: Handbook of Health Economics. Elsevier, pp. 1141-1174.

Weisbrod, B.A., 1991. The Health Care Quadrilemma: An Essay on Technological Change, Insurance, Quality of Care, and Cost Containment. Journal of Economic Literature 29, 523-552.

Wolfers, J., 2006. Did Unilateral Divorce Laws Raise Divorce Rates? A Reconciliation and New Results. American Economic Review, American Economic Association 96(5), 1802-1820.

Zuckerman, S., Williams, A.F., Stockley, K.E., 2009. Trends In Medicaid Physician Fees, 2003-2008. Health Affairs 28, w510-w519. 
Figure 1: State-Level Changes in NICU Provision by Medicaid Eligibility Changes, 1985 - 1996

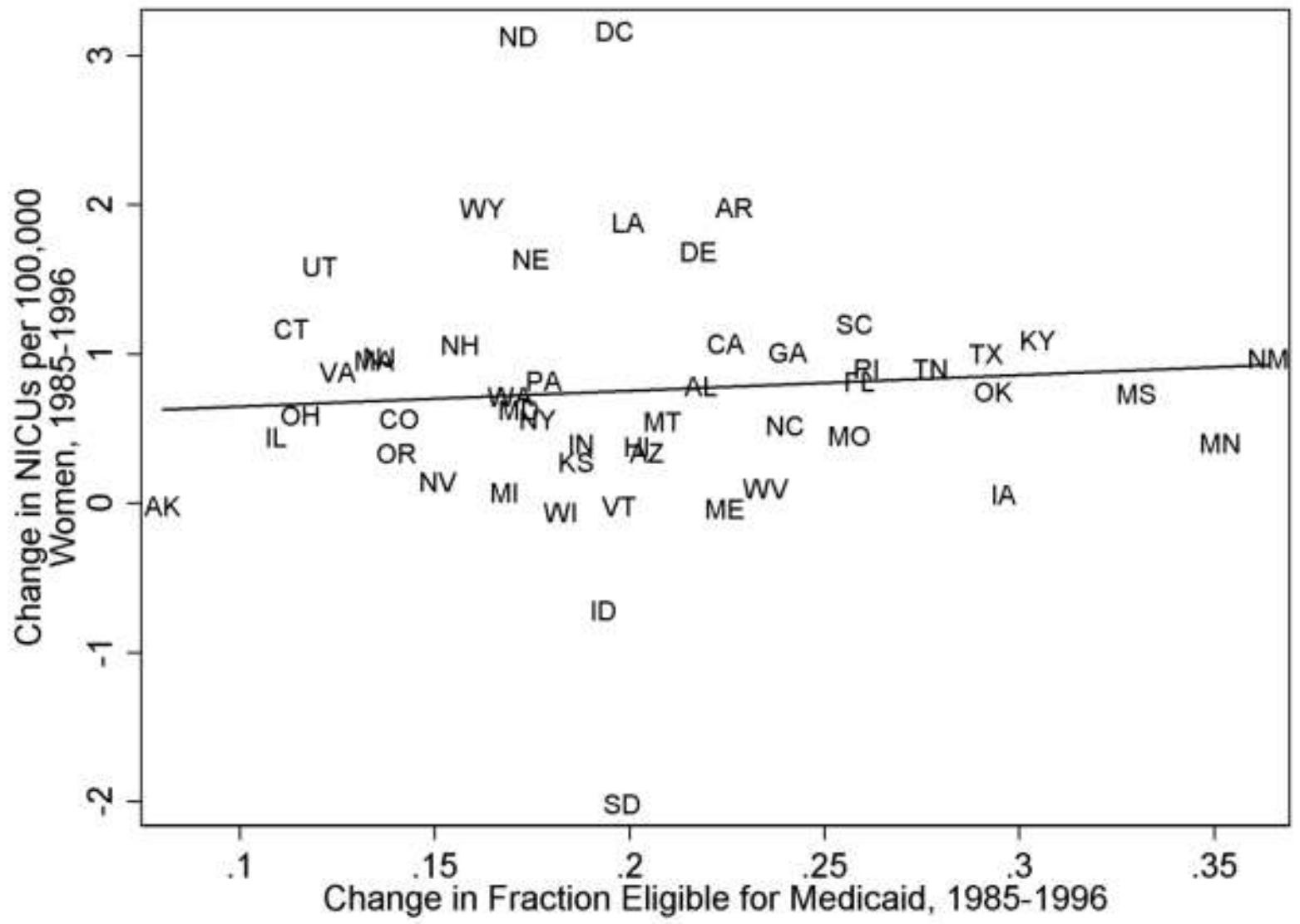

Notes: This figure plots changes in the number of hospitals that offer NICUs per 100,000 women of childbearing age against changes in the fraction of women in a fixed sample from the CPS that would be eligible for Medicaid conditional on pregnancy, under that state's eligibility rules. Changes are calculated between 1985 and 1996 for each state. The line represents the best linear fit, weighted by the number of women of childbearing age in 1985 . 
Figure 2: State-Level Changes in NICU Provision by Medicaid Eligibility Changes - Groups of States Stratified by Fee Ratio and Insurance Rate

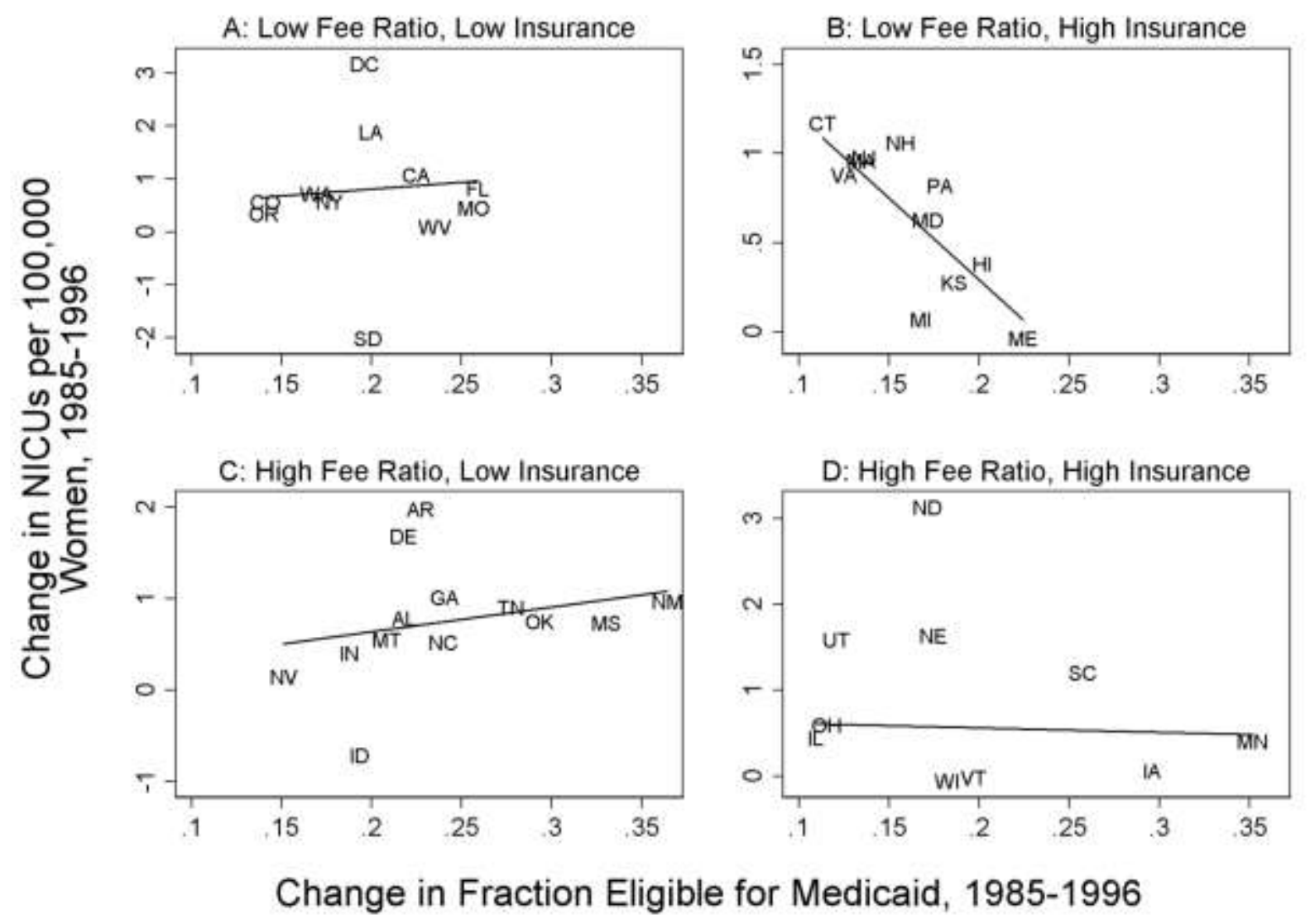

Notes: This figure plots changes in number of hospitals that offer NICUs per 100,000 women of childbearing age against changes in the fraction of women in a fixed sample from the CPS that would be eligible for Medicaid conditional on pregnancy, under that state's eligibility rules. Changes are calculated between 1985 and 1996. The line represents the best linear fit weighted by the number of women of childbearing age in 1985. States are divided based on whether their 1985 insurance rate and 1985 Medicaid-to-private-obstetric-fee ratio are above or below the median. 
Figure 3: Effects of State Medicaid Eligibility Level on Hospital NICU Provision by 1985 State Insurance Rate

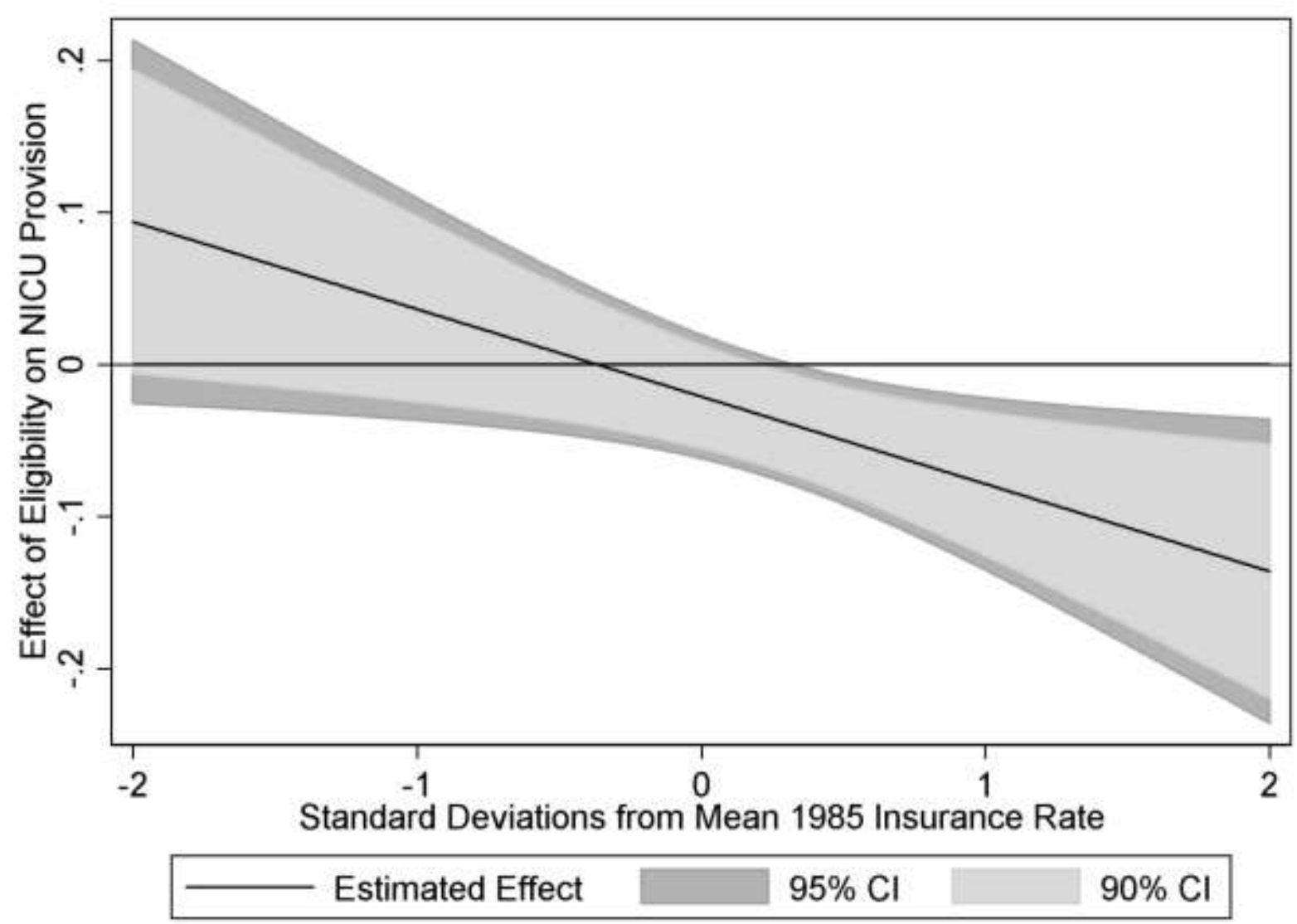

Notes: This figure plot the estimated effect of state Medicaid eligibility on the probability that a hospital offers a NICU for different values of the baseline state-level insurance rate, along with 95 percent and 90 percent confidence intervals. Baseline insurance is normalized to reflect the number of standard deviations from the sample mean. Estimates are from the regression reported in Panel A and Column 7 of Table 4 and control for hospital fixed effects; year dummies; state-specific time trends; county level controls for number of births, number of low birth weight births, infant mortality rate, population, female population by age, and per-capita income; and an interaction between baseline insurance rate and a linear year trend. Standard errors are clustered at the state level. 
Table 1: Summary Statistics by Year

\begin{tabular}{ccccc}
\hline Year & $\begin{array}{c}\text { Number of } \\
\text { Hospitals }\end{array}$ & $\begin{array}{c}\text { Number of } \\
\text { Hospitals } \\
\text { with a } \\
\text { NICU }\end{array}$ & $\begin{array}{c}\text { Fraction of } \\
\text { Hospitals } \\
\text { with a NICU }\end{array}$ & $\begin{array}{c}\text { Mean } \\
\text { State } \\
\text { Medicaid } \\
\text { Eligibility }\end{array}$ \\
\hline 1985 & 3,993 & 589 & 0.148 & 0.097 \\
1986 & 3,957 & 627 & 0.158 & 0.111 \\
1987 & 3,893 & 655 & 0.168 & 0.128 \\
1988 & 3,830 & 707 & 0.185 & 0.190 \\
1989 & 3,784 & 735 & 0.194 & 0.232 \\
1990 & 3,728 & 742 & 0.199 & 0.254 \\
1991 & 3,679 & 760 & 0.207 & 0.257 \\
1992 & 3,635 & 777 & 0.214 & 0.268 \\
1993 & 3,597 & 794 & 0.221 & 0.279 \\
1994 & 3,557 & 847 & 0.238 & 0.280 \\
1995 & 3,510 & 854 & 0.243 & 0.310 \\
1996 & 3,450 & 857 & 0.248 & 0.310 \\
\hline
\end{tabular}

Notes: Number and fraction of hospitals with a NICU are calculated from the AHA data. Sample includes hospitals with an active obstetric unit at the beginning of the time period. Mean state Medicaid eligibility is the mean at the year level for our hospital sample. 
Table 2: Summary Statistics of County-Level Characteristics

\begin{tabular}{lrr}
\hline & Mean & $\begin{array}{r}\text { Standard } \\
\text { Deviation }\end{array}$ \\
\hline County-Level Infant Health Controls & & \\
Number of Births & 8,860 & 26,247 \\
Number of Low Birth Weight Births & 636 & 1,803 \\
County-Level Population Controls & & \\
Population & 500,842 & $1,341,186$ \\
Female Population by Age & & \\
15 to 19 & 17,495 & 46,964 \\
20 to 24 & 20,413 & 56,747 \\
25 to 29 & 22,771 & 63,297 \\
30 to 34 & 22,225 & 60,653 \\
35 to 44 & 37,663 & 100,042 \\
45 to 54 & 26,773 & 70,159 \\
55 to 59 & 11,282 & 28,916 \\
60 to 64 & 10,823 & 27,326 \\
65 to 74 & 18,515 & 45,861 \\
Per Capita Income (\$) & 16,910 & 5,264 \\
Baseline Socioeconomic Characteristics & & \\
State-Level Insurance (\%) & 82.545 & 4.284 \\
County-Level Employment Rate (\%) & 91.880 & 3.446 \\
County-Level Above Federal Poverty Line (\%) & 85.821 & 6.283 \\
$\mathbf{N}$ & 44,613 & \\
\hline
\end{tabular}

Notes: All variables are calculated from the Area Resource File, except for State-Level Insurance, which is drawn from the March Supplement of the Current Population Survey. Baseline characteristics reflect 1985 levels. 
Table 3: Aggregate State-Level Effect of State Medicaid Eligibility on NICU Provision

\begin{tabular}{|c|c|c|c|c|c|c|c|}
\hline & $(1)$ & $(2)$ & (3) & (4) & (5) & (6) & (7) \\
\hline \multicolumn{8}{|c|}{ Panel A: Full Sample (N=612) } \\
\hline \multirow[t]{2}{*}{ Eligibility } & 0.167 & 0.176 & -0.072 & -0.165 & -0.179 & -0.034 & -0.129 \\
\hline & $(0.300)$ & $(0.243)$ & $(0.167)$ & $(0.259)$ & $(0.232)$ & $(0.216)$ & $(0.141)$ \\
\hline Eligibility X & & & & $-0.560 * *$ & -0.354 & $-0.454 * *$ & $-0.354 * *$ \\
\hline 1985 Insurance Rate & & & & $(0.187)$ & $(0.231)$ & $(0.186)$ & $(0.168)$ \\
\hline \multicolumn{8}{|c|}{ Panel B: Low-Medicaid/Private-Fee-Ratio States $(\mathrm{N}=\mathbf{2 6 4})$} \\
\hline \multirow[t]{2}{*}{ Eligibility } & -0.021 & 0.002 & -0.093 & -0.167 & -0.181 & -0.237 & -0.036 \\
\hline & $(0.461)$ & $(0.423)$ & $(0.189)$ & $(0.431)$ & $(0.395)$ & $(0.279)$ & $(0.258)$ \\
\hline Eligibility X & & & & $-0.820 *$ & -0.760 & $-0.892 * *$ & $-0.685 * *$ \\
\hline 1985 Insurance Rate & & & & $(0.424)$ & $(0.488)$ & $(0.406)$ & $(0.318)$ \\
\hline \multicolumn{8}{|c|}{ Panel C: High-Medicaid/Private-Fee-Ratio States $(\mathrm{N}=\mathbf{2 7 6})$} \\
\hline \multirow[t]{2}{*}{ Eligibility } & 0.220 & 0.092 & -0.124 & 0.113 & 0.027 & 0.094 & -0.118 \\
\hline & $(0.455)$ & $(0.279)$ & $(0.244)$ & $(0.386)$ & $(0.396)$ & $(0.273)$ & $(0.219)$ \\
\hline Eligibility X & & & & -0.331 & 0.201 & -0.013 & 0.042 \\
\hline 1985 Insurance Rate & & & & $(0.259)$ & $(0.359)$ & $(0.361)$ & $(0.314)$ \\
\hline Year Dummies & $\mathrm{X}$ & $\mathrm{X}$ & $\mathrm{X}$ & $\mathrm{X}$ & $\mathrm{X}$ & $\mathrm{X}$ & $\mathrm{X}$ \\
\hline 1985 Insurance X Year & & & & & $\mathrm{X}$ & $\mathrm{X}$ & $\mathrm{X}$ \\
\hline Other Controls & & $\mathrm{X}$ & $\mathrm{X}$ & & & $\mathrm{X}$ & $\mathrm{X}$ \\
\hline State Trends & & & $\mathrm{X}$ & & & & $\mathrm{X}$ \\
\hline \multicolumn{8}{|c|}{$\begin{array}{l}\text { Notes: Each column presents coefficient estimates from separate regressions of the number of NICUs per } 100,000 \\
\text { women of childbearing age in a given sate and year on the fraction of women eligible for Medicaid in the state and } \\
\text { year. The number of NICUs per 100,000 women of childbearing age is calculated from all non-federal, general acute } \\
\text { care hospitals in the AHA data. Regressions are weighted by the number of women of childbearing age in } 1985 \text {. } \\
\text { Panel A includes all states. Panel B includes states with Medicaid to private obstetric fee ratios below } 0.41 \text {, and } \\
\text { Panel C includes states with fee ratios above } 0.41 \text {. In Columns } 4-7 \text { eligibility is interacted with the state-level } \\
\text { baseline (1985) insurance rate. All regressions include state and year fixed effects, and each column progressively } \\
\text { adds additional controls. Controls include an interaction between baseline insurance and a linear year trend (in the } \\
\text { interaction models); state-level controls for number of births, number of low birth weight births, population, female } \\
\text { population by age and per-capita income; and state-specific time trends. Standard errors are clustered at the state } \\
\text { level. } \\
* *-p<.05, *-p<.10\end{array}$} \\
\hline
\end{tabular}


Table 4: Hospital-Level Effect of State Medicaid Eligibility on NICU Provision

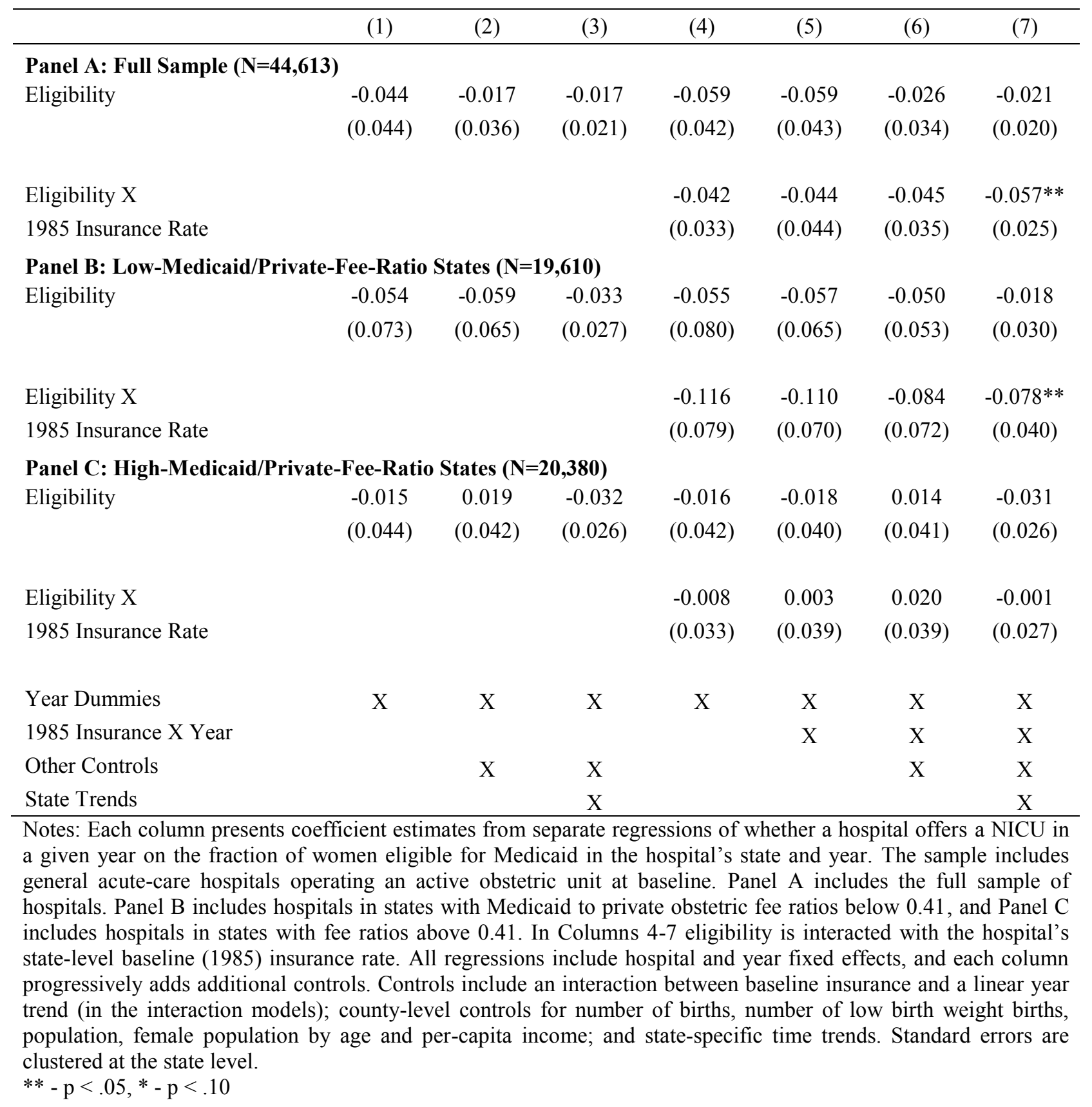


Table 5: Timing of Medicaid Eligibility Effect on NICU Provision

\begin{tabular}{|c|c|c|c|c|c|c|}
\hline & \multicolumn{2}{|c|}{ All States } & \multicolumn{2}{|c|}{$\begin{array}{c}\text { Low } \\
\text { Medicaid/Private } \\
\text { Fee-Ratio States }\end{array}$} & \multicolumn{2}{|c|}{$\begin{array}{c}\text { High } \\
\text { Medicaid/Private } \\
\text { Fee-Ratio States }\end{array}$} \\
\hline & (1) & (2) & (3) & (4) & $(5)$ & (6) \\
\hline \multicolumn{7}{|l|}{ This Year: } \\
\hline \multirow[t]{2}{*}{ Eligibility } & 0.017 & -0.019 & 0.048 & -0.007 & -0.019 & -0.033 \\
\hline & $(0.021)$ & $(0.019)$ & $(0.032)$ & $(0.026)$ & $(0.020)$ & $(0.028)$ \\
\hline Eligibility $\mathrm{X}$ & $-0.081 * *$ & $-0.046^{*}$ & $-0.102 * *$ & $-0.073 * *$ & $-0.032 * *$ & 0.004 \\
\hline 1985 Insurance Rate & $(0.021)$ & $(0.025)$ & $(0.038)$ & $(0.029)$ & $(0.016)$ & $(0.030)$ \\
\hline \multicolumn{7}{|l|}{2 Years Later: } \\
\hline \multirow[t]{2}{*}{ Eligibility } & -0.019 & & -0.005 & & $-0.035 * *$ & \\
\hline & $(0.022)$ & & $(0.031)$ & & $(0.017)$ & \\
\hline Eligibility X & -0.022 & & -0.005 & & -0.010 & \\
\hline 1985 Insurance Rate & $(0.024)$ & & $(0.022)$ & & $(0.022)$ & \\
\hline \multicolumn{7}{|l|}{2 Years Prior: } \\
\hline \multirow[t]{2}{*}{ Eligibility } & & -0.005 & & 0.002 & & 0.003 \\
\hline & & $(0.021)$ & & $(0.045)$ & & $(0.032)$ \\
\hline Eligibility X & & $-0.034 *$ & & $-0.086^{* *}$ & & -0.001 \\
\hline 1985 Insurance Rate & & $(0.020)$ & & $(0.043)$ & & $(0.028)$ \\
\hline $\mathrm{N}$ & 36,663 & 36,663 & 16,115 & 16,115 & 16,775 & 16,775 \\
\hline
\end{tabular}

Notes: Each column presents coefficient estimates from separate regressions. All regressions include hospital fixed effects; year dummies; county-level controls for number of births, number of low birth weight births, population, female population by age and per-capita income; state-specific time trends; and an interaction between baseline insurance and a linear year trend. Standard errors are clustered at the state level.

$* *-\mathrm{p}<.05, *-\mathrm{p}<.10$ 
Table 6: Effect of Medicaid Eligibility on Cardiac Care Provision

\begin{tabular}{|c|c|c|}
\hline & Cath Lab & $\begin{array}{c}\text { Open Heart } \\
\text { Surgery }\end{array}$ \\
\hline \multicolumn{3}{|c|}{ Panel A: Full Sample $(\mathrm{N}=46,197)$} \\
\hline Eligibility & $\begin{array}{c}0.029 \\
(0.043)\end{array}$ & $\begin{array}{l}-0.003 \\
(0.014)\end{array}$ \\
\hline $\begin{array}{l}\text { Eligibility X } \\
1985 \text { Insurance Rate }\end{array}$ & $\begin{array}{l}-0.007 \\
(0.027)\end{array}$ & $\begin{array}{l}-0.002 \\
(0.011)\end{array}$ \\
\hline \multicolumn{3}{|c|}{ Panel B: Low-Medicaid/Private-Fee Ratio States $(N=\mathbf{1 8 , 8 8 0})$} \\
\hline Eligibility & $\begin{array}{l}-0.018 \\
(0.085)\end{array}$ & $\begin{array}{l}-0.015 \\
(0.026)\end{array}$ \\
\hline $\begin{array}{l}\text { Eligibility X } \\
1985 \text { Insurance Rate }\end{array}$ & $\begin{array}{l}-0.040 \\
(0.046)\end{array}$ & $\begin{array}{c}0.029 \\
(0.019)\end{array}$ \\
\hline \multicolumn{3}{|c|}{ Panel C: High-Medicaid/Private-Fee Ratio States $(N=19,793)$} \\
\hline Eligibility & $\begin{array}{c}0.065 * * \\
(0.033)\end{array}$ & $\begin{array}{l}-0.002 \\
(0.015)\end{array}$ \\
\hline $\begin{array}{l}\text { Eligibility X } \\
1985 \text { Insurance Rate }\end{array}$ & $\begin{array}{c}0.030 \\
(0.031)\end{array}$ & $\begin{array}{l}-0.016 \\
(0.016)\end{array}$ \\
\hline
\end{tabular}

Notes: Each column presents coefficient estimates from separate regressions of whether a hospital offers a certain type of Cardiac care related technologies in a given year on the fraction of women eligible for Medicaid in the hospital's state and year and eligibility interacted with baseline insurance rates. Panel A includes the full sample of hospitals. Panel B includes hospitals in states with Medicaid to private obstetric fee ratios below 0.41, and Panel C includes hospitals in states with fee ratios above 0.41. All regressions include hospital fixed effects; year dummies; county level controls for number of births, number of low birth weight births, population, female population by age and per-capita income; state specific linear year trends; and an interaction between baseline insurance and a linear year trend. Standard errors are clustered at the state level.

$* *-\mathrm{p}<.05, *-\mathrm{p}<.10$ 
Table 7: Medicaid Eligibility and Hospital Exit

\begin{tabular}{|c|c|c|c|}
\hline & $\begin{array}{l}\text { Hospital Exit from } \\
\text { Sample of All } \\
\text { General, Acute-Care } \\
\text { Hospitals } \\
\end{array}$ & $\begin{array}{c}\text { Analysis } \\
\text { Sample } \\
\text { Attrition }\end{array}$ & $\begin{array}{l}\text { Analysis } \\
\text { Sample } \\
\text { Attrition w/ } \\
\text { NICUs } \\
\end{array}$ \\
\hline & $(1)$ & (2) & (3) \\
\hline \multicolumn{4}{|c|}{ Panel A: Full Sample (N=612) } \\
\hline Eligibility & $\begin{array}{l}-0.178 \\
(0.130)\end{array}$ & $\begin{array}{l}-0.059 \\
(0.145)\end{array}$ & $\begin{array}{l}-0.035 \\
(0.056)\end{array}$ \\
\hline $\begin{array}{l}\text { Eligibility X } \\
1985 \text { Insurance } \\
\text { Rate }\end{array}$ & $\begin{array}{c}0.062 \\
(0.136)\end{array}$ & $\begin{array}{l}-0.029 \\
(0.138)\end{array}$ & $\begin{array}{l}-0.014 \\
(0.032)\end{array}$ \\
\hline \multicolumn{4}{|c|}{ Panel B: Low-Medicaid/Private-Fee-Ratio States $(\mathrm{N}=\mathbf{2 6 4})$} \\
\hline Eligibility & $\begin{array}{l}-0.055 \\
(0.116)\end{array}$ & $\begin{array}{l}-0.133 \\
(0.173)\end{array}$ & $\begin{array}{l}-0.070 \\
(0.074)\end{array}$ \\
\hline $\begin{array}{l}\text { Eligibility X } \\
1985 \text { Insurance } \\
\text { Rate }\end{array}$ & $\begin{array}{l}-0.036 \\
(0.104)\end{array}$ & $\begin{array}{l}-0.074 \\
(0.150)\end{array}$ & $\begin{array}{l}-0.025 \\
(0.054)\end{array}$ \\
\hline \multicolumn{4}{|c|}{ Panel C: High-Medicaid/Private-Fee-Ratio States $(\mathrm{N}=\mathbf{2 7 6})$} \\
\hline Eligibility & $\begin{array}{l}-0.262 \\
(0.260)\end{array}$ & $\begin{array}{c}0.043 \\
(0.313)\end{array}$ & $\begin{array}{l}-0.043 \\
(0.108)\end{array}$ \\
\hline $\begin{array}{l}\text { Eligibility X } \\
1985 \text { Insurance } \\
\text { Rate }\end{array}$ & $\begin{array}{c}0.077 \\
(0.273)\end{array}$ & $\begin{array}{l}-0.074 \\
(0.299) \\
\end{array}$ & $\begin{array}{c}0.015 \\
(0.077)\end{array}$ \\
\hline
\end{tabular}

Notes: Each column presents coefficient estimates from separate regressions. The dependent variables are calculated at the state-year level and scaled by the number of women of childbearing age (in 100,000s). Column 1 includes exits from the sample of all non-federal, general acute care hospitals in the AHA data. Columns 2 and 3 include the raw number of hospitals leaving the analysis sample and the number of exiting hospitals operating a NICU, respectively. Panel A includes all states. Panel B includes states with Medicaid to private obstetric fee ratios below 0.41 , and Panel C includes states with fee ratios above 0.41. All regressions include state and year fixed effects; an interaction between baseline insurance and a linear year trend; state-level controls for number of births, number of low birth weight births, population, female population by age and per-capita income; and state-specific time trends. Standard errors are clustered at the state level.

$* *-\mathrm{p}<.05, *-\mathrm{p}<.10$ 
Table 8: Robustness Tests

\begin{tabular}{|c|c|c|c|c|c|c|}
\hline & & \multicolumn{4}{|c|}{ Balanced All } & \multirow{3}{*}{$\begin{array}{c}\text { Assume } \\
\text { NICUs Do } \\
\text { Not Close } \\
(6)\end{array}$} \\
\hline & Baseline & $\begin{array}{l}\text { Balanced } \\
\text { Panel }\end{array}$ & $\begin{array}{c}\text { All } \\
\text { Hospitals }\end{array}$ & $\begin{array}{c}\text { Hospital } \\
\text { Panel }\end{array}$ & $\begin{array}{l}\text { Weighted } \\
\text { Results }\end{array}$ & \\
\hline & (1) & (2) & (3) & (4) & $(5)$ & \\
\hline \multicolumn{7}{|l|}{ Panel A: Full Sample } \\
\hline Eligibility & $\begin{array}{l}-0.021 \\
(0.020)\end{array}$ & $\begin{array}{l}-0.015 \\
(0.022)\end{array}$ & $\begin{array}{l}-0.017 \\
(0.016)\end{array}$ & $\begin{array}{l}-0.010 \\
(0.018)\end{array}$ & $\begin{array}{l}-0.033 \\
(0.041)\end{array}$ & $\begin{array}{l}-0.019 \\
(0.020)\end{array}$ \\
\hline $\begin{array}{l}\text { Eligibility X } \\
1985 \text { Insurance Rate }\end{array}$ & $\begin{array}{c}-0.057 * * \\
(0.025)\end{array}$ & $\begin{array}{c}-0.066^{* *} \\
(0.027)\end{array}$ & $\begin{array}{l}-0.040^{*} \\
(0.022)\end{array}$ & $\begin{array}{c}-0.053 * * \\
(0.021)\end{array}$ & $\begin{array}{c}-0.144 * * \\
(0.037)\end{array}$ & $\begin{array}{c}-0.055^{* *} \\
(0.025)\end{array}$ \\
\hline $\mathrm{N}$ & 44,613 & 41,400 & 62,505 & 54,538 & 43,515 & 44,613 \\
\hline \multicolumn{7}{|c|}{ Panel B: Low-Medicaid/Private-Fee-Ratio States } \\
\hline Eligibility & $\begin{array}{l}-0.018 \\
(0.030)\end{array}$ & $\begin{array}{l}-0.007 \\
(0.034)\end{array}$ & $\begin{array}{l}-0.006 \\
(0.028)\end{array}$ & $\begin{array}{l}-0.005 \\
(0.031)\end{array}$ & $\begin{array}{l}-0.046 \\
(0.043)\end{array}$ & $\begin{array}{l}-0.016 \\
(0.027)\end{array}$ \\
\hline $\begin{array}{l}\text { Eligibility X } \\
1985 \text { Insurance Rate }\end{array}$ & $\begin{array}{c}-0.078 * * \\
(0.040)\end{array}$ & $\begin{array}{l}-0.082 * \\
(0.044)\end{array}$ & $\begin{array}{l}-0.067 * \\
(0.036)\end{array}$ & $\begin{array}{l}-0.068 * \\
(0.036)\end{array}$ & $\begin{array}{c}-0.157 * * \\
(0.064)\end{array}$ & $\begin{array}{c}-0.079 * * \\
(0.036)\end{array}$ \\
\hline $\mathrm{N}$ & 19,610 & 18,120 & 28,981 & 24,782 & 19,204 & 19,610 \\
\hline \multicolumn{7}{|c|}{ Panel C: High-Medicaid/Private-Fee-Ratio States } \\
\hline Eligibility & $\begin{array}{l}-0.031 \\
(0.026)\end{array}$ & $\begin{array}{l}-0.033 \\
(0.027)\end{array}$ & $\begin{array}{l}-0.030 \\
(0.025)\end{array}$ & $\begin{array}{l}-0.024 \\
(0.023)\end{array}$ & $\begin{array}{l}-0.018 \\
(0.041)\end{array}$ & $\begin{array}{l}-0.030 \\
(0.025)\end{array}$ \\
\hline $\begin{array}{l}\text { Eligibility X } \\
1985 \text { Insurance Rate }\end{array}$ & $\begin{array}{l}-0.001 \\
(0.027)\end{array}$ & $\begin{array}{l}-0.011 \\
(0.028)\end{array}$ & $\begin{array}{l}0.013 \\
(0.024)\end{array}$ & $\begin{array}{l}-0.007 \\
(0.024)\end{array}$ & $\begin{array}{l}-0.038 \\
(0.043)\end{array}$ & $\begin{array}{c}0.003 \\
(0.026)\end{array}$ \\
\hline $\mathrm{N}$ & 20,380 & 19,068 & 26,049 & 23,397 & 19,801 & 20,380 \\
\hline
\end{tabular}

Notes: Each column presents coefficient estimates from separate regressions of whether a hospital offers a NICU in a given year on the fraction of women eligible for Medicaid in the hospital's state and year. Column 1 repeats our baseline results. Column 2 uses a balanced sample of hospitals from our baseline sample present in the data for all 12 years. Column 3 uses the full sample of non-federal, general acute-care hospitals in the AHA data, and Column 4 uses the balanced subset of these hospitals present in the data for all 12 years. Column 5 presents results weighted by the number of births delivered by each hospital in 1985. Column 6 constructs the dependent variable by assuming that NICUs do not close. All regressions include hospital fixed effects; year dummies; county-level controls for number of births, number of low birth weight births, population, female population by age and per-capita income, state-specific time trends and an interaction between baseline insurance and a linear year trend. Standard errors are clustered at the state level.

$* *-\mathrm{p}<.05, *-\mathrm{p}<.10$ 
Table 9: Heterogeneity

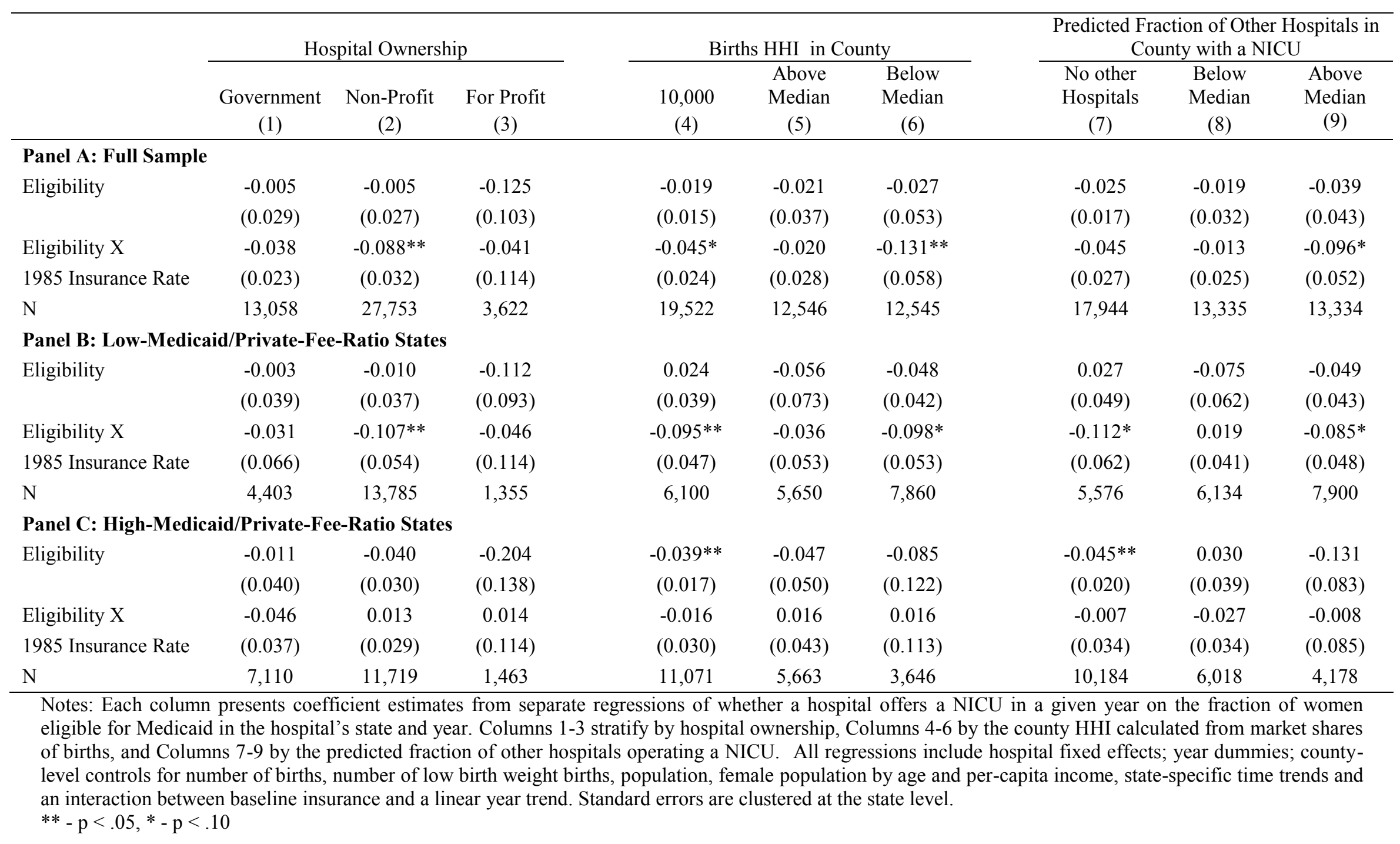


Table 10: Effect of Medicaid Eligibility on County-Level Low-Birth-Weight Infant Mortality

\begin{tabular}{lcc}
\hline & $(1)$ & $(2)$ \\
\hline Panel A: Full Sample (N=1,593) & -0.011 & -0.011 \\
Eligibility & $(0.008)$ & $(0.008)$ \\
& & \\
Eligibility X & & -0.001 \\
1985 Insurance Rate & $(0.005)$ \\
& & \\
Panel B: Low-Medicaid/Private-Fee Ratio States & $(\mathbf{N}=\mathbf{1 , 0 1 0})$ \\
Eligibility & -0.013 & -0.014 \\
& $(0.010)$ & $(0.010)$ \\
Eligibility X & & 0.002 \\
1985 Insurance Rate & $(0.007)$ \\
Panel C: High-Medicaid/Private-Fee Ratio States & $(\mathbf{N}=\mathbf{4 6 2})$ \\
Eligibility & 0.004 & 0.005 \\
& $(0.011)$ & $(0.011)$ \\
Eligibility X & & -0.000 \\
1985 Insurance Rate & $(0.011)$ \\
\hline
\end{tabular}

Notes: Each column presents coefficient estimates from separate regressions of county level infant mortality rates on the fraction of women eligible for Medicaid in the state and year. Panel A includes the full sample of counties. Panel $\mathrm{B}$ includes counties in states with Medicaid to private obstetric fee ratios below 0.41 , and Panel C includes counties in states with fee ratios above 0.41. All regressions include county fixed effects; year dummies; state-specific linear time trends; county level controls for number of births, number of low birth weight births, population, female population by age, and per-capita income. They also include county-level averages of individual-level infant characteristics including mother's age, race, and education; sex of the infant; and multiple birth status. Standard errors are clustered at the state level.

$* *-\mathrm{p}<.05, *-\mathrm{p}<.10$ 


\section{Appendix 1: AHA Data-Cleaning Steps}

In our full sample of AHA data spanning 1980 to 2000, 6 percent of hospital-year observations have missing values for the number of neonatal intensive- or intermediate-care beds. However, it is often the case that the same hospital will have reported a value for the number of beds for the year before and after the missing value. If a cell is missing intensive- or intermediate-care beds but the values for that hospital in the year before and after are the same, we use that value to fill in the missing cell. This step fills in about half of the missing values in those variables; only about 3 percent of hospital-year observations are missing values for either of the two bed variables in our final data set, which spans 1985 to 1996 .

Second, we define the NICU indicator variable as one if the number of total neonatal intermediate- and neonatal intensive-care beds is greater than zero. The NICU indicator is thus initially missing for 3 percent of observations. However, since we only need to know whether the number of beds is positive for this indicator, we can apply the "before and after" rule by looking at the number of beds variable here to fill in additional missing values for this indicator variable; this step fills in about one third of the remaining 3 percent of cells with missing values for NICU indicator. Third, we fill in any additional missing values of the indicator variable if its previous two years have the same value. The above procedures fill in most of the missing values in the data. There are about 100 to 150 observations ( 0.13 percent of the total observation) that remain missing after this step, and we fill in those remaining missing values with the previous year's value.

In addition to missing values, we also observe a small number of instances of inconsistent reporting of whether or not a hospital has NICU beds from year to year. It is unlikely that a hospital will intermittently have a NICU on a yearly basis, so we use two rules to address this inconsistency in reporting in the created NICU dummy variable. Rule A is to convert zeros to ones if a hospital's reported beds indicate no NICU in three or fewer consecutive years but indicate a NICU in the year (s) right after or before. We then similarly convert ones to zeros if a hospital indicates a NICU in three or fewer consecutive years but no NICU in the surrounding years. Rule B creates an alternative series by reversing 
these two steps, first converting intervals of ones to zeros and then intervals of zeros to ones. To decide which rule is used for each hospital, we use the count of zeros and ones after we see the first transition (either from one to zero or zero to one) in the raw data. If the number of ones is equal to or bigger than the number of zeros, we apply rule A; otherwise we apply rule B. ${ }^{39}$ This correction for intermittent NICU reporting changes less than 1 percent $(892 / 78,824)$ of observations in the data at the hospital-year level, and about 12 percent $(497 / 4,125)$ of the hospitals are affected. Also note that we perform this data cleaning on the full panel of data from 1980 to 2000, even though our analysis sample only includes 1985 through 1996. Therefore, even if a short interval of zeros or ones occurs at the beginning or end of our analysis sample, we are able to use additional data from outside the analysis period to verify and correct inconsistent reporting.

\section{Appendix 2: Extending Medicaid-to-physician-fee-ratio series}

In order to control for time-varying differences in fee ratios in our sample, we extend the Currie et al. (1995) data initially collected for 1985-1993 to include $1994-1996 .^{40}$ For 1993 through 1996, we collect Medicaid fees from a survey of states conducted by Bradley Gray and Kosali Simon. The fee we use covers the total OB/GYN reimbursement for a vaginal delivery. Unfortunately, the AHA financial data used to adjust the private fees according to hospital-cost growth are now restricted and not easily obtainable. Instead, we obtain data from the American Medical Association Socioeconomic Monitoring System on physician-office-visit reimbursements. These data report the mean physician-office-visit fee from private payers annually by census division. They also report the annual nationwide average $\mathrm{OB} / \mathrm{GYN}$ office visit reimbursement. We therefore calculate multiple versions of the Medicaid-to-private

\footnotetext{
${ }^{39}$ We use a simple example to illustrate how we correct the data using the rules. For example, we observe in the data that a hospital's NICU indicator variable has values across time of 001000100. Applying Rule A leads to 001111100, and applying Rule B leads to 000000000. In the example, the first transition happens at year 3, the count of zeros after year 3 is 5 , and the count of ones is 2 . Since the hospital has more zeros than ones, we use Rule B to adjust the data.

${ }^{40}$ The numerator of the Currie et al. (1995) index captures state-level Medicaid fees paid to OB/GYNs gathered from various sources. The denominator is based on state-level private fees for vaginal deliveries in 1989 as collected by Schwartz et al. (1991). Currie et al. (1995) then use financial data from the American Hospital Association to inflate and deflate this fee for previous and subsequent years based on hospital-cost growth.
} 
fee ratio for 1993-1996 using three different inflators to project the denominator of Currie et al. (1995)'s 1992 value forward. Fee ratio 1 inflates the denominator utilizing the census-division-level growth rate of physician-office-visit reimbursements. Fee ratio 2 utilizes the nationwide growth rate of $\mathrm{OB} / \mathrm{GYN}$ office visit fees. Fee ratio 3 calculates the average growth rate of the denominator by state from 1985-1992 from Currie et al. (1995)'s data and applies this average growth rate to subsequent years by state. Fee data is missing for Alaska, Arizona, Kentucky, Rhode Island, Texas, and Wyoming, so we exclude these states from analysis incorporating these fee indices.

Appendix Figure 1 shows mean Medicaid Obstetric Fees and the three Medicaid-to-private fee ratios over time. Medicaid fees trend upward over the time period, and the ratio trends upward as well until 1993 when it begins to fall, as Medicaid fees grow more slowly than private fees.

Appendix Table 3 presents results controlling for the ratio of Medicaid-to-private obstetric reimbursement rates. Regardless of which version of the fee ratio is used, the results in low- and high-fee ratio states are almost identical to our main estimates. The full sample results do not have a statistically significant interaction effect, mostly driven by the slightly different sample, since fee data are unavailable for six states. The fee ratio itself has a positive but not statistically significant effect on NICU provision. The fact that the coefficient estimates of eligibility and the interaction terms are unchanged suggests that our estimates do not appear to confound any changes to Medicaid payment rates with the changes in Medicaid eligibility associated with the expansions. 
Appendix Figure 1: Medicaid Obstetric Fee and Medicaid to Private Fee Ratio, 1985-1996

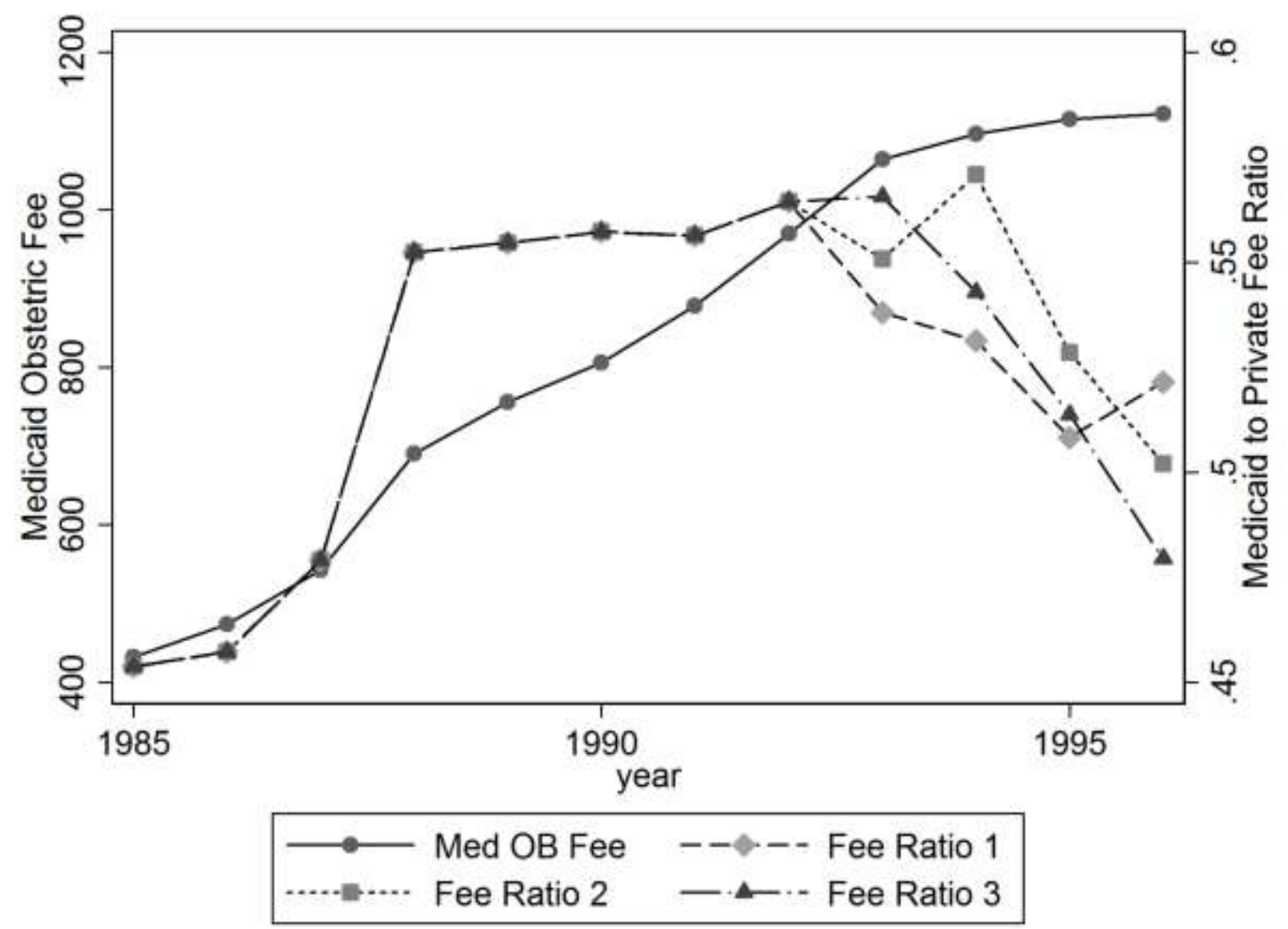

Notes: Fee Ratio 1 inflates private fees after 1992 using census-division-level physician-office-visit fees. Fee Ratio 2 inflates private fees using nationwide obstetric-office-visit fees. Fee Ratio 3 inflates private fees using the average growth rate of private fees prior to 1992. 


\section{Appendix Table 1: Additional Crowd-Out Proxies}

\begin{tabular}{|c|c|c|c|}
\hline & $\begin{array}{l}\text { Insurance } \\
\text { Interaction }\end{array}$ & $\begin{array}{c}\text { Employment } \\
\text { Interaction }\end{array}$ & $\begin{array}{l}\%>\mathrm{FPL} \\
\text { Interaction }\end{array}$ \\
\hline & (1) & (2) & (3) \\
\hline \multicolumn{4}{|c|}{ Panel A: Full Sample $(\mathrm{N}=44,613)$} \\
\hline Eligibility & $\begin{array}{l}-0.021 \\
(0.020)\end{array}$ & $\begin{array}{l}-0.021 \\
(0.020)\end{array}$ & $\begin{array}{l}-0.025 \\
(0.019)\end{array}$ \\
\hline Eligibility X & $-0.057 * *$ & -0.036 & -0.033 \\
\hline Crowd-Out Proxy & $(0.025)$ & $(0.028)$ & $(0.023)$ \\
\hline \multicolumn{4}{|c|}{ Panel B: Low-Medicaid/Private-Fee-Ratio States $(\mathrm{N}=19,610)$} \\
\hline Eligibility & $\begin{array}{l}-0.018 \\
(0.030)\end{array}$ & $\begin{array}{l}-0.036 \\
(0.031)\end{array}$ & $\begin{array}{l}-0.024 \\
(0.028)\end{array}$ \\
\hline Eligibility X & $-0.078 * *$ & $-0.053 *$ & $-0.065^{*}$ \\
\hline Crowd-Out Proxy & $(0.040)$ & $(0.032)$ & $(0.035)$ \\
\hline \multicolumn{4}{|c|}{ Panel C: High-Medicaid/Private-Fee-Ratio States $(\mathrm{N}=\mathbf{2 0 , 3 8 0})$} \\
\hline Eligibility & $\begin{array}{l}-0.031 \\
(0.026)\end{array}$ & $\begin{array}{l}-0.026 \\
(0.028)\end{array}$ & $\begin{array}{l}-0.028 \\
(0.028)\end{array}$ \\
\hline $\begin{array}{l}\text { Eligibility X } \\
\text { Crowd-Out Proxy }\end{array}$ & -0.001 & 0.027 & 0.006 \\
\hline Crowd-Out Proxy & $(0.027)$ & $(0.030)$ & $(0.021)$ \\
\hline
\end{tabular}

Notes: Each column presents coefficient estimates from separate regressions of whether a hospital offers a NICU in a given year on the fraction of women eligible for Medicaid in the hospital's state and year. Panel A includes the full sample of hospitals. Panel B includes hospitals in states with Medicaid to private obstetric fee ratios below 0.41 and Panel $\mathrm{C}$ includes hospitals in states with fee ratios above 0.41. In Column 1 eligibility is interacted with the hospital's state-level baseline (1985) insurance rate. In Column 2 eligibility is interacted with the county-level baseline (1985) employment rate (1 minus the unemployment rate). In Column 3 eligibility is interacted with the hospital's county-level baseline (average of 1979 and 1989) fraction above the federal poverty line. All regressions include hospital fixed effects; year dummies; county-level controls for number of births, number of low birth weight births, infant mortality rate, population, the female population by age, and per-capita income; state-specific linear year trends; and an interaction between baseline insurance, employment, or fraction above poverty line and a linear year trend. Standard errors are clustered at the state level.

$* *-\mathrm{p}<.05, *-\mathrm{p}<.10$ 


\section{Appendix Table 2: Effects of State Medicaid Eligibility on NICU Provision by 1985 Medicaid/Private-Fee Ratio Categories, and 1985 Insurance Rate Categories}

\begin{tabular}{lc}
\hline & $(1)$ \\
\hline Eligibility X Low Ratio X & 0.008 \\
Low Insurance & $(0.047)$ \\
& \\
Eligibility X Low Ratio X & $-0.126^{* *}$ \\
High Insurance & $(0.045)$ \\
Eligibility X High Ratio X & -0.011 \\
Low Insurance & $(0.038)$ \\
Eligibility X High Ratio X & -0.040 \\
High Insurance & $(0.026)$ \\
$\mathrm{N}$ & 39,990 \\
\hline
\end{tabular}

Notes: This table separates states into four groups based on whether their 1985 Medicaid to private obstetric fee ratio is above or below the median and whether their 1985 insurance rate is above or below the median. Estimates are from a regression of whether a hospital offers a NICU in a given year on the fraction of women eligible for Medicaid in the hospitals state and year interacted with dummy variables for these four categories. Standard errors are clustered at the state level.

$* *-\mathrm{p}<.05, *-\mathrm{p}<.10$ 


\section{Appendix Table 3: Controlling for Medicaid/Private Fee Ratios}

\begin{tabular}{|c|c|c|c|c|}
\hline & $\begin{array}{c}\text { Fee } \\
\text { Sample } \\
\\
(1)\end{array}$ & $\begin{array}{l}\text { Census } \\
\text { Div. } \\
\text { Physician } \\
\text { Fee } \\
\text { Growth } \\
\text { (2) }\end{array}$ & $\begin{array}{c}\text { National } \\
\text { OB Fee } \\
\text { Growth } \\
\text { (3) }\end{array}$ & $\begin{array}{c}\text { Projected } \\
\text { AHA } \\
\text { Fee } \\
\text { Growth } \\
(4)\end{array}$ \\
\hline \multicolumn{5}{|c|}{ Panel A: Full Sample $(\mathrm{N}=39,990)$} \\
\hline Eligibility & $\begin{array}{l}-0.033^{*} \\
(0.020)\end{array}$ & $\begin{array}{l}-0.037^{*} \\
(0.020)\end{array}$ & $\begin{array}{c}-0.038^{*} \\
(0.020)\end{array}$ & $\begin{array}{l}-0.038^{*} \\
(0.020)\end{array}$ \\
\hline Eligibility X & -0.029 & -0.028 & -0.027 & -0.028 \\
\hline 1985 Insurance Rate & $(0.022)$ & $(0.022)$ & $(0.022)$ & $(0.022)$ \\
\hline Fee Ratio & & $\begin{array}{c}0.013 \\
(0.014)\end{array}$ & $\begin{array}{c}0.017 \\
(0.014)\end{array}$ & $\begin{array}{c}0.017 \\
(0.014)\end{array}$ \\
\hline \multicolumn{5}{|c|}{ Panel B: Low-Medicaid/Private-Fee-Ratio States $(N=19,610)$} \\
\hline Eligibility & $\begin{array}{l}-0.018 \\
(0.030)\end{array}$ & $\begin{array}{l}-0.022 \\
(0.029)\end{array}$ & $\begin{array}{l}-0.021 \\
(0.029)\end{array}$ & $\begin{array}{l}-0.021 \\
(0.029)\end{array}$ \\
\hline $\begin{array}{l}\text { Eligibility X } \\
1985 \text { Insurance Rate }\end{array}$ & $\begin{array}{c}-0.078 * * \\
(0.040)\end{array}$ & $\begin{array}{c}-0.077 * * \\
(0.038)\end{array}$ & $\begin{array}{c}-0.077 * * \\
(0.039)\end{array}$ & $\begin{array}{c}-0.077 * * \\
(0.039)\end{array}$ \\
\hline Fee Ratio & & $\begin{array}{c}0.013 \\
(0.021)\end{array}$ & $\begin{array}{c}0.011 \\
(0.021)\end{array}$ & $\begin{array}{c}0.009 \\
(0.021)\end{array}$ \\
\hline \multicolumn{5}{|c|}{ Panel C: High-Medicaid/Private-Fee-Ratio States $(\mathrm{N}=\mathbf{2 0 , 3 8 0})$} \\
\hline Eligibility & $\begin{array}{l}-0.031 \\
(0.026)\end{array}$ & $\begin{array}{l}-0.037 \\
(0.028)\end{array}$ & $\begin{array}{l}-0.040 \\
(0.027)\end{array}$ & $\begin{array}{l}-0.041 \\
(0.028)\end{array}$ \\
\hline $\begin{array}{l}\text { Eligibility X } \\
1985 \text { Insurance Rate }\end{array}$ & $\begin{array}{l}-0.001 \\
(0.027)\end{array}$ & $\begin{array}{c}0.002 \\
(0.027)\end{array}$ & $\begin{array}{c}0.003 \\
(0.027)\end{array}$ & $\begin{array}{c}0.003 \\
(0.027)\end{array}$ \\
\hline Fee Ratio & & $\begin{array}{c}0.019 \\
(0.020)\end{array}$ & $\begin{array}{c}0.029 \\
(0.020)\end{array}$ & $\begin{array}{c}0.028 \\
(0.020)\end{array}$ \\
\hline
\end{tabular}

Notes: Each column presents coefficient estimates from separate regressions of whether a hospital offers a NICU in a given year on the fraction of women eligible for Medicaid in the hospital's state and year. Each column includes a control of alternative versions of Medicaid to private obstetric fees described in Appendix 2. All regressions include hospital fixed effects; year dummies; county-level controls for number of births, number of low birth weight births, population, female population by age and per-capita income, state-specific time trends and an interaction between baseline insurance and a linear year trend. Standard errors are clustered at the state level.

$* *-\mathrm{p}<.05, *-\mathrm{p}<.10$ 